\title{
BLOGS Y NARCOTRÁFICO: ANÁLISIS DE CONTENIDO DE LOS MENSAJES DE LA CRIMINALIDAD ORGANIZADA EN MÉXICO
}

Patricia Liliana Cerda Pérez1: Universidad Autónoma de Nuevo León. México. cerda35@hotmail.com

José Gregorio Jr. Alvarado Pérez: Universidad Autónoma de Nuevo León. México. greg_alvarado@hotmail.com

\section{RESUMEN}

Páginas "especializadas" en difundir crímenes y hasta homicidios en vivo perpetrados por miembros de los cárteles del crimen organizado en la zona Noreste de México, obtienen miles de visitas de internautas diariamente. Las mafias mexicanas a través de blogs divulgados en la red, mezclan y difunden información proveniente de medios periodísticos, con rumores y amenazas dirigidas a grupos mafiosos contrarios o hasta el propio Estado mexicano. Esta es la realidad analizada durante el desarrollo del presente trabajo. En estos sitios, el ciudadano común observa desde su computadora o celular, ejecuciones, atentados; cuerpos inertes decapitados, ahorcados o mutilados; conoce las disputas entre los grupos de la criminalidad organizada; accede a videos y fotografías donde se publicita las torturas y violaciones hechas sobre personas secuestradas civiles o plagiados de grupos contrarios. Conoce virtualmente las armas, automóviles, joyas y estilos de vida de quienes trabajan para las mafias. Aquí, en la red, los delincuentes exhiben impunemente sus crímenes; las víctimas son mostradas en su dolor con fotografías y videos tomados por la propia criminalidad y, todo ello, sucede en medio de páginas que tienen publicidad con marcas de prestigio a través del servicio de "hosting", en su mayoría gratuitos. Los narcotraficantes operantes en el Noreste de México, mayoritariamente pertenecientes a los grupos denominados "los Zetas" o del "Cártel del Golfo", han encontrado en las redes de internautas un modo para hacer sentir sus alcances y poderío a través de la guerra no sólo de armas, sino también mediática, donde el internet es un poderoso artefacto bélico para llegar a la ciudadanía; amedrentar a sus oponentes y hasta desafiar al Estado mexicano en materia de seguridad pública y nacional.

$1 \quad 1$ Patricia Liliana Cerda Pérez: Investigadora y Catedrática de la Facultad de Ciencias de la Comunicación de la Universidad Autónoma de Nuevo León. Coordinadora del Centro de Investigación de la FCC de la UANL. Miembro del Sistema Nacional de Investigadores de CONACYT, Nivel II. 
PALABRAS CLAVE

Narcotráfico - Crimen organizado - Blogs - Violencia - Inseguridad - Cobertura Mediática - Amarillismo - Periodismo - Blogging.

\title{
BLOGS AND DRUG TRAFFICKING: CONTENT ANALYSIS OF MESSAGES OF ORGANIZED CRIME IN MEXICO
}

\begin{abstract}
The pages "specialized" in spreading live crimes and even murders committed by members of organized crime cartels in northeastern Mexico get thousands of visits from Internet users daily. The Mexican Mafias, through blogs disseminated in the web, mix and spread information from newspapers with rumors and threats against rival Mafia groups or even the Mexican State. This reality is what is discussed in this paper. On these sites, through his computer or cell phone, the ordinary citizen watches executions, attacks, inert beheaded, hanged or mutilated bodies; knows about the disputes between organized crime groups; accesses videos and pictures where the torture and rape of kidnapped civilians or members of opposing groups is advertised. He virtually knows about weapons, cars, jewelry and lifestyles of those who work for the Mafia. In such sites, criminals show their crimes with impunity; victims are shown in their pain with photographs and videos taken by the criminals themselves and all this happens in advertising pages of prestigious brands through the hosting services, most of them are free. Drug traffickers operating in northeastern Mexico, mainly belonging to the groups called "Los Zetas" or "Gulf Cartel", have found in the networks of Internet users a way to show their scope and power through war, not only weapons but also the media, where the Internet is a powerful weapon of war to reach the public, scare their opponents and even challenge the Mexican State as regards public and national security.
\end{abstract}

\section{KEY WORDS}

Drug trafficking - Organized Crime - Blogs - Violence - Insecurity - Media Coverage - Sensationalism - Journalism - Blogging.

\section{INTRODUCCIÓN}

Los medios tradicionales regidos teóricamente por principios éticos y códigos deontológicos, limitan la publicación de contenidos en los que se muestren de manera explícita hechos violentos a través de los cuales se exalte la morbosidad o el amarillismo.

La difusión de contenidos violentos, sin embargo subsiste en múltiples espacios. Hoy, con el surgimiento de los blogs y de los espacios libres en internet, cualquier persona, con un mínimo de conocimiento informático, es capaz de distribuir contenidos en línea de cualquier índole. 
Los sitios con alto contenido violento y sin censura, donde se muestran crímenes y atentados perpetrados por células del crimen organizado mexicano, despiertan interés entre la audiencia internauta.

Estos novedosos medios informáticos, representan también un vehículo para que la criminalidad organizada difunda mensajes de toda índole. Textos, videos y fotografías con contenido explícitamente violento son distribuidas en páginas de internet sin censura y, comúnmente, esta información es reproducida en las redes sociales, convirtiéndose en un fenómeno viral.

Entre estos sitios destacan los denominados "blogdelnarco.com"; "tierradelnarco.com" e "historiasdelnarco.com". En estas páginas, los administradores publican "narcomensajes", videos, textos e imágenes de los crímenes efectuados por los grupos de la criminalidad organizada en el noreste de México. Estos sitios cuentan con una cantidad considerable de usuarios que los visitan con la finalidad de conocer los últimos sucesos relacionados con el narcotráfico. Esta información no cuenta con las características propias del rigor periodístico, los datos que circulan en la red no siempre sean fidedignos.

Estas páginas, -según se publica en las mismas-, son administradas por ciudadanos comunes, quienes desde su óptica argumentan que difunden este tipo de información que usualmente en el diarismo suele ser eliminada no sólo por la exaltación de la violencia y el morbo que en ellas se hace, sino también porque al difundirse se coloca en riesgo a periódicos y periodistas frente a los embates que contra la prensa suelen realizar algunos miembros de la criminalidad organizada en México.

A través de esta investigación se analizan el tipo de información que la criminalidad organizada da a conocer a través de las redes y la forma en la que ésta, es publicada en tres de los principales blogs dedicados a difundir información derivada de los crímenes cometidos por las células del crimen organizado en la región noreste de la República Mexicana, integrada por las entidades de Nuevo León; Coahuila y Tamaulipas.

\subsection{Marco teórico}

Según la Real Academia de la Lengua Española (2014), las bitácoras digitales, ciberbitácoras, ciberdiarios o weblogs, conocidos comúnmente como "blogs" son "sitios web que incluyen, a modo de diario personal de su autor o autores, contenidos de su interés, actualizados con frecuencia y a menudo comentados por los lectores".

\subsubsection{Antecedentes: Origen y evolución de los blogs}

Previo al surgimiento de los blogs, proliferaron en la red las comunidades digitales y programas para crear foros en internet, en los que cuales los usuarios podían entablar conversaciones en "hilos"; es decir, una serie de mensajes que están relacionados con el tema principal del foro.

Los blogs, tal como los conocemos actualmente, son el descendiente directo de los diarios en línea; sitios en donde los usuarios difundían en la red todo lo que ocurría 
en su vida personal. En sus inicios, los blogs eran versiones actualizadas de sitios web comunes; sin embargo, la evolución de estas herramientas facilitó el proceso de publicar información en la red, dirigiéndose a un público más amplio, aún y cuando éstas no tuvieran conocimientos técnicos.

Estos sitios pueden construirse y almacenarse usando servicios de alojamiento de blogs, pueden ser creados a través de herramientas como Blogger o WordPress o mediante servicios de hosting corrientes. Usualmente, estos espacios son gratuitos para los usuarios de la red.

Entre las características que fincaron la proliferación de estos sitios se encuentran la posibilidad de publicar contenido en periodos de tiempo cortos; admiten comentarios de los lectores y permiten el desarrollo de una comunidad en torno al autor, posibilitando la comunicación bilateral.

El éxito de los blogs se debe a la posibilidad brindada a los usuarios de convertirse en generadores de contenidos y de proveer un espacio libre y gratuito donde cualquier ciudadano puede verter sus opiniones respecto a cualquier tema de su interés.

\subsubsection{Los blogs como herramientas periodísticas}

En el mundo mediático los periodistas y los medios solo competían con otros periodistas y medios por la información que en ellos se publicaba. Es decir, la tarea informativa, se centraba entre organizaciones mediáticas y profesionales de la información. En este escenario, la audiencia no tenía ninguna forma de intervenir, el proceso era unilateral.

El desarrollo de los medios a través de la red; la evolución de la tecnología; la facilidad de las herramientas web y el sencillo acceso a las mismas, han provocado que los ciudadanos, los usuarios de los medios, estén en condiciones de aportar datos y de convertirse en productores de contenido a través de la red. Así mismo, estos sitios representan para los periodistas un espacio de expresión alejado del rigor de las reglas impuestas por las organizaciones periodísticas para las que éstos laboran. Este hecho provoca que en internet, temas que no se abordan en los medios tradicionales, encuentren un lugar de difusión a través del cual llegan a una gran público.

Al respecto, Cruccianelli (2013) señala que:

Temas que no encontraban espacio en los medios masivos (mass media), ya sea por razones editoriales o publicitarias o de mero desinterés por parte de los editores, van ganando cada vez más espacio a partir de los hallazgos de la audiencia, y su no inclusión en las rutinas informativas acrecienta el riesgo de minar el principal capital de los periodistas y los medios: su credibilidad. Simplemente, porque se alejan de la realidad, una realidad que hoy está más expuesta y es difícil de ocultar.

La posibilidad de publicar en línea sin ninguna restricción permite que los periodistas encuentren un sitio donde divulgar sus ideas. Entre la diversidad de temas, en la red, es posible encontrar un sitio especializado para cada uno de ellos. Además, los blogs también representan una forma de comunicación y retroalimentación entre los periodistas y lectores. 
Por otra parte, el desarrollo de estos sitios en internet dio paso al surgimiento del denominado "periodismo ciudadano". Un esquema de participación bilateral en el que los usuarios, comúnmente pasivos, se convierten en agentes activos en el proceso de generación y difusión de información.

La información divulgada mediante estas vías carece del rigor propio de la profesión periodística. Ésta no es un producto derivado de un proceso exhaustivo de investigación y de contrastación de fuentes, donde veracidad y calidad son los pilares fundamentales de su construcción.

Es aquí, donde se fundamentan los principales detractores del periodismo ciudadano. Pues quienes se desempeñan profesionalmente en este oficio sostienen que para su correcto desarrollo debe haber una metodología y una técnica para ejercerlo. Al respecto, Monsivaís (2005) escribía que:

Con la llegada de internet, en la década de los noventa se repite el esquema de la sorpresa creativa y se aprende de nuevo sobre la marcha, se extrae de la práctica la teoría que luego, curiosamente, la práctica rectifica. Otra vez, los adelantos tecnológicos son tan extraordinarios que la interpretación convincente tarda en llegar y suele ser no convincente. Internet, medio de información y comunicación, transforma radicalmente el panorama al concederle un papel al usuario. Cada quien, si se lo propone, es su propio director de noticiero.

Por su parte, Dario Restrepo sostiene que:

Ni los "twiteros", ni los "grafiteros", ni los "bloggeros", no los que tienen cuenta activa en Facebook pueden llamarse periodistas por razones de estas actividades comunicativas. Es cierto que comunican con públicos que pueden llegar a ser más extensos que los de cualquier periódico; que pueden comunicarse con mayor frecuencia que un periódico; que pueden tener la misma periodicidad en su comunicación, de un periódico. Sin embargo, no son periodistas.

Según las opiniones de Monsivaís y de Restrepo, la información publicada en los blogs no puede considerarse periodística. Usualmente, las noticias difundidas en estos sitios se limitan a reproducir datos divulgados en otros medios o se constituyen en un espacio de opinión donde los periodistas pueden emitir sus opiniones sin las limitaciones impuestas por el medio periodístico al que pertenecen.

Si bien los blogs representan un área de oportunidad para el ejercicio periodístico; cuando son mal empleados pueden provocar efectos negativos en la audiencia. Tal es el caso de los blogs encaminados a la difusión de información relacionada con el narcotráfico donde se muestran imágenes, videos y fotografías que evidencian, sin censura, la crudeza de los crímenes perpetuados por las células del crimen organizado. 


\subsubsection{El periodismo en tiempos del narco}

Actualmente, la sociedad mexicana vive un clima de inseguridad sin precedentes en la historia del país. Específicamente, el incremento de la violencia en la región noreste de México, representó para los ciudadanos que habitan esta área un hecho que trastocó prácticamente todos los aspectos de la sociedad y que incrementó, en gran medida, el miedo y la percepción de inseguridad.

Hechos violentos, asesinatos, balaceras a plena luz del día y crímenes consumados por células del crimen organizado, eran el panorama que debían enfrentar los ciudadanos del noreste mexicano, durante los últimos cinco años. Mediáticamente, estos sucesos acapararon las portadas de diarios y los titulares de los noticieros transmitidos en la región.

Mónica Medel (2010) señala que la información respecto al narcotráfico en México estuvo basada en reportes de decomisos y homicidios aislados publicadas en las páginas interiores de los diarios. Sin embargo, el aumento en los asesinatos, las masacres y el nivel de brutalidad (torturas, decapitaciones y desmembramientos) provocaron que esta información tuviera un mayor énfasis, situándola en las primeras planas de los diarios.

Este panorama de violencia ha implicado problemas y desafíos derivados del morbo y lenguaje empleado en la cobertura de estos hechos. Asimismo, la importancia dada por los medios de comunicación a este tipo de hechos los ha convertido en los "órganos de comunicación" de los cárteles, quienes a través de las denominadas "narco mantas" hacen llegar sus mensajes y amenazas al gobierno, las bandas rivales y a los ciudadanos.

La saturación mediática y la sobre exposición a estos contenidos provoca que la audiencia se acostumbre a la violencia, con notas en las que no se exploran los motivos ni se le da un rostro humano a la información, tal como sucede con aquellas noticias en las que se hacen recuentos de cifras de muertos sin contexto social ni histórico (Medel, 2010).

Ante tal situación, la prensa mexicana y la cobertura de la violencia derivada del narcotráfico enfrenta una serie de retos que afectan directamente el tipo de historias que se escriben respecto a este fenómeno, así como su calidad.

Los medios de comunicación también debieron cambiar su forma de operación ante esta situación, pues estaban situados en medio de presiones, amenazas y atentados directos por parte de las células del crimen organizado; principalmente, en aquellas zonas del país que sirven como rutas para el contrabando de drogas hacia Estados Unidos. Esto provocó que al incrementarse el nivel de crudeza en los hechos, la información dejará de ser divulgada en los medios de comunicación.

Según Mónica Medel (2010) el margen de operación de los medios mexicanos no es fácil, por lo cual han tenido que tomar la decisión de ir reduciendo el material que publica, a la par de aumentar la autocensura a fin de proteger a la integridad del medio y de los periodistas. La autora sostiene que:

El oficio de reportero se ha vuelto a tal punto riesgoso que sesenta periodistas han sido asesinados en México desde el año 2000 al 2010, doce de ellos solo en el 2009, mientras que hasta abril de 2010 se ha informado del homicidio de 
otros cinco, según datos oficiales. Ocho más se encuentran desaparecidos y, en el mismo período, siete medios de comunicación han sufrido atentados explosivos, lo que ha convertido a México en uno de los países más peligrosos del mundo para ejercer el periodismo. (pag.14)

Esta combinación de factores, el clima de violencia e inseguridad y la operación de cárteles del narcotráfico en diversas áreas de México ha afectado también negativamente en la cobertura de información y en la calidad de las notas divulgadas al respecto o, en su caso, a "silencios prolongados" (Medel, 2010) por parte de las redacciones.

En el encuentro denominado "Cobertura transfronteriza del narcotráfico entre Estados Unidos y México" organizado en el año 2010 por el Centro Knight para el Periodismo en las Américas (Universidad de Texas en Austin), se analizaron las principales deficiencias y dificultades enfrentadas por los periodistas que ejercen esta profesión en las regiones de México donde operan los cárteles del narcotráfico.

Entre las principales deficiencias se mencionó el lenguaje utilizado para informar; el morbo y las simplificaciones al aceptar como válidos ciertos estereotipos. Según las conclusiones emitidas en el citado encuentro...

En el mejor de los casos, el tipo de nota que termina cubriendo -la versión oficial constreñida al conteo de víctimas y sin contexto socioeconómico e histórico- es sólo el coctel de estos factores. En el peor, es un apagón informativo tras el homicidio de periodistas alentado por el miedo que se instala en el resto de sus colegas.

En este panorama en el que los medios de comunicación se encontraban amenazados, surgió una nueva forma de difusión de este tipo de información. Los blogs y sitios gratuitos a través de la red se convirtieron en la manera en la que estas noticias eran divulgadas a la audiencia. Empero, la información difundida en estos sitios carecía de censura. Las imágenes crudas de asesinatos, decapitaciones y mutilaciones estaban a la orden del día.

En sus inicios, estos sitios gozaron una gran popularidad entre los usuarios de internet; principalmente, porque en ellos podían encontrar información que de otra forma era imposible obtener al ser censurada en los diarios y noticieros tradicionales. Uno de los principales blogs, enfocados fundamentalmente a difusión de noticias relacionadas con los crímenes del narcotráfico es el denominado "Blog del Narco". Este sitio, que opera desde el 2 de marzo de 2010, tiene como objetivo según sus creadores:

La idea de crear Blog del Narco surge cuando los medios de comunicación y el gobierno intentan aparentar que en México no pasa nada, debido a que los medios están amenazados y el gobierno aparentemente comprado, fue que decidimos crear un medio de comunicación con el cual podamos dar a conocer a la gente que es lo que pasa, redactar los acontecimiento exactamente tal cual fueron, sin alteraciones o modificaciones a nuestra conveniencia. 
Como se mencionó anteriormente, los blogs son espacios donde cualquier persona, aún con escaso conocimiento técnico e informático, puede convertirse en un generador de contenido y publicar el contenido que desee en la red aún y cuando éste no cuente con el rigor propio de la labor periodística. Información sin sustento, derivada de chismes o rumores de redes sociales y sin la investigación propia del ejercicio de esta profesión son el común denominador de estos sitios en los que el control de calidad en la información no existe.

En ese sentido, los autores del "Blog del narco" sostienen que su intención es "publicar las notas de manera periodística"; sin embargo aclaran:

Somos conscientes que sólo somos un blog "casero", cuya finalidad es la de informar (lamentablemente para muchos), con mucha mayor eficacia, veracidad y mejor documentación que la de muchos otros sitios y periodistas profesionales. Esforzándonos hasta en detalles como el corregir la ortografía, redacción y el diseño de "los grandes", para que sea el lector quien resulte beneficiado al ser debidamente informado y no a medias o condicionado.

Así mismo, destacan, que el uso de esta herramienta de comunicación contribuye a la libertad de expresión y que la información divulgada a través de estos sitios no obedece a los intereses de ninguna corporación periodística o a algún grupo del crimen organizado:

No ha sido, ni es, ni será nunca nuestra intención la de competir con las grandes empresas que se dedican al $100 \%$ a publicar las noticias locales, estatales y nacionales por lo cual, suponemos, les pagan. Nos referimos concretamente a que son empleados que sólo cumplen órdenes. Acá es distinto... Podemos quizá, ser "piratas", pero jamás peones ni esclavos. Somos libres y como tal nos expresamos. No servimos a ningún tipo de interés ni estamos a los pies de nadie. Ni nos pagan por publicar o dejar de publicar tal y cual cosa según nos convenga. Ni lo hacemos bajo ningún tipo de presión o amenaza, mucho menos compramos o vendemos al mejor postor.

Según los administradores de este sitio, divulgar la información relacionada con los crímenes cometidos por las células del crimen organizado permite que la sociedad este mejor informada y que conozca lo que sucede a su alrededor. Para ello se vale de información de otros sitios y la enriquece para ofrecer las mejores noticias a los usuarios.

Este es un modesto blog que no pretende engañar a nadie. No es una agencia noticiosa y a pesar de ello, está mucho mejor documentado e informa mejor que muchas de ellas. Desde su encabezado reitera que toma lo mejor de unos sitios y enriquece la información con otros. Y si hasta quienes se consideran defensores de sus "propios y exclusivos" detenidos, ejecutados, "levantados", heridos, secuestrados, liberados, accidentados, encarcelados y una gran lista de etcéteras, voltean a vernos, se incomodan al visitarnos o simplemente checan lo que hacemos, es señal que no lo estamos haciendo mal... 
Las nuevas tecnologías de la información y las herramientas derivadas de las mismas abren nuevos canales para la difusión de noticias y datos relevantes respecto a los sucesos que se presentan en un área o región, el narcotráfico y el crimen organizado en ese sentido, no han sido la excepción.

\section{OBJETIVOS}

Analizar el tipo y la forma en la que son publicados los mensajes en los blogs enfocados a difundir la información respecto a los crímenes perpetrados por el crimen organizado en la región noreste de México. Los específicos se centran en Analizar la frecuencia con la que son divulgados sucesos relacionados con los crímenes cometidos por células del crimen organizado en los blogs y sitios especializados en esta información; examinar si la información presentada en estos sitios y blogs respecto a las acciones de las células del crimen organizado cumple con los requisitos básicos de la redacción periodística (firma periodística y estructura); evaluar el origen (fuente), clasificación y cantidad de material (videos, fotografías y/o audios) respecto a los delitos cometidos por grupos organizado de la criminalidad divulgados a través de estos sitios; analizar la forma de operación de las bandas del crimen organizado (principales hechos delictivos, móviles, armamento) cuyas acciones delictivas son divulgadas a través de sitios especializados y blogs; explorar cuál es el perfil (personal y delictivo) de los individuos que integran las células del crimen organizado y cuál es su función dentro de estos grupos, así como sus antecedentes delictivos y criminológicos; evaluar la forma en la que se menciona la participación de Corporaciones de Seguridad en los hechos delictivos perpetuados por miembros del crimen organizado; así como el nivel al que estas pertenecen (municipal, estatal o federal).

\section{METODOLOGÍA}

El presente trabajo parte de un enfoque exploratorio-descriptivo encaminado a analizar los contenidos y la forma en que éstos son divulgados a través de páginas y blogs especializados en información de crímenes y atentados realizados por grupos de la delincuencia organizada en la zona Noreste de México.

Para la realización del análisis exploratorio-descriptivo-transeccional, se utiliza una técnica de análisis de contenido de 261 notas publicadas en tres diferentes blogs (historiasdelnarco.com; blogdelnarco.es; tierradelnarco.com) de los cuales solo se examinará la información divulgada correspondiente a los estados de Nuevo León, Tamaulipas y Coahuila. La población considerada para esta investigación corresponde a toda la información publicada a través de blogs y páginas no oficiales respecto a los atentados y crímenes cometidos por miembros del crimen organizado en México, dentro de la zona Noreste del país.

Para esta investigación se consideraron 261 notas publicadas entre agosto del 2013 y junio del 2014, respecto a hechos delictivos cometidos por células del crimen organizado en la región noreste de México. Tales hechos fueron difundidos a través de los blogs enfocados a la difusión de este tipo de información denominados historiasdelnarco.com; blogdelnarco.es y tierradelnarco.com. 
Tabla 1. Notas analizadas por estado.

\begin{tabular}{lccc}
\hline & \multicolumn{3}{c}{ Estado } \\
\cline { 2 - 4 } Blog & Nuevo León & Tamaulipas & Coahuila \\
\hline Blog del Narco & 22 notas & 19 notas & 22 notas \\
Historias del Narco & 20 notas & 42 notas & 25 notas \\
Tierra del Narco & 10 notas & 93 notas & 9 notas \\
\hline Total & 52 notas & 154 notas & 56 notas \\
\hline & & Fuente: Elaboración propia (2014)
\end{tabular}

El análisis de contenido de las noticias publicadas en los blogs donde se difunde información relacionada con el narcotráfico se realizará desde las siguientes perspectivas de análisis o categorías:

1. Presentación de la nota en el blog.

2. Estructura de la noticia.

3. Información respecto al fenómeno que se publica.

4. Participación de corporaciones de seguridad.

5. Perfil del narcotraficante y de la célula del crimen organizado de la cual se informa.

Se examinaron 261 notas difundidas a propósito de los delitos cometidos por cárteles y células del crimen organizado. Con este propósito se consultaron las páginas denominadas "El Blog del Narco"; "Tierra del Narco" e "Historias del Narco". El análisis de contenido comprende la información publicada en dichos sitios de agosto de 2013 a junio de 2014 y fue realizado con la participación del grupo de estudiantes de la unidad de aprendizaje de Periodismo de Investigación y Opinión impartida por la Dra. Patricia Liliana Cerda Pérez en el período Agosto - Diciembre 2014 Se desarrolló un formato de codificación a través del cual se analizaron las variables e indicadores en las 261 notas relacionadas con el crimen organizado publicadas en los blogs y páginas especializadas en el narcotráfico.

Para el procesamiento de datos de esta investigación se realizó en primera instancia una evaluación documental de los blogs y páginas especializadas en difundir información relacionada con el narcotráfico. Ello, con la finalidad de encontrar aquellas notas en las se divulgaron acontecimientos consumados en la región noreste de México.

Posteriormente, una vez identificadas estas notas, se analizaron y se clasificaron en un formato específicamente diseñado para este objetivo. Por último, los resultados de este análisis fueron incluidos en una base de datos diseñada en el programa estadístico SPSS (Stadistical Package for the Social Sciences, versión 20) para su procesamiento estadístico y para la elaboración de tablas y gráficas que permitan ilustrar lo encontrado en este trabajo. 


\section{RESULTADOS}

De las 261 noticias publicadas en blogs especializados en divulgar los crímenes de la delincuencia organizada en México; los resultados indican que el sitio denominado "tierradelnarco.com" tuvo mayor actividad durante el período de tiempo analizado al contabilizar 109 notas (41.8 por ciento del total analizado); seguido de "historiasdelnarco.com" con 89 notas (34.1 por ciento) y el "blogdelnarco.com" con 63 notas (24 por ciento).

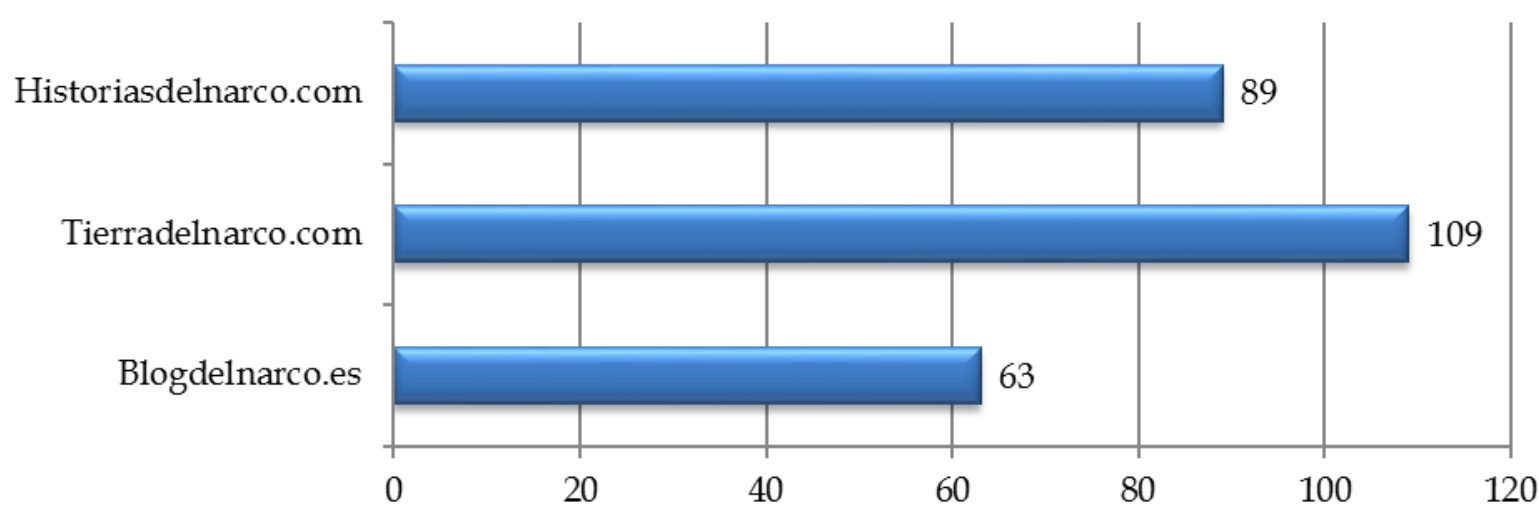

Gráfico 1. Blog de publicación

Fuente: Elaboración propia (2014)

En este análisis que comprende las notas publicadas en los tres sitios antes descritos desde el mes de mayo de 2013 hasta julio de 2014, se encontró que para el año 2013, la mayor cantidad de información violenta se publicó durante los meses de octubre y noviembre con 19 noticias; mientras que para el año 2014 fueron durante los meses de mayo y junio con 48 y 63 notas, respectivamente.

En el periodo comprendido entre octubre de 2013 a junio 2014 se registra el mayor índice de publicación de noticias relacionadas con el crimen organizado en estos sitios al contabilizar un total de 194 notas (74.3 por ciento). Un gran porcentaje de estas informaciones (23.4 por ciento), son retomadas de noticias publicadas en diversos diarios de la localidad o bien revistas y periódicos de alcance nacional.

Tabla 2. Fecha de publicación de las notas publicadas en los blogs

\begin{tabular}{lllllll}
\hline \multirow{2}{*}{ Mes } & 2013 & & 2014 & \multicolumn{3}{c}{ Frecuencia } \\
\cline { 2 - 7 } & Frec. & Pctje. & Frec. & Pctje. & Frec. & Pctje. \\
\hline Enero & 0 & 0.0 & 17 & 8.6 & 17 & 6.5 \\
Febrero & 0 & 0.0 & 15 & 7.6 & 15 & 5.7 \\
Marzo & 0 & 0.0 & 23 & 11.6 & 23 & 8.8 \\
Abril & 0 & 0.0 & 26 & 13.1 & 26 & 10.0 \\
Mayo & 1 & 1.6 & 48 & 24.2 & 49 & 18.8 \\
Junio & 1 & 1.6 & 63 & 31.8 & 64 & 24.5 \\
Julio & 0 & 0.0 & 1 & 0.5 & 1 & 0.4 \\
Agosto & 1 & 1.6 & 0 & 0.0 & 1 & 0.4 \\
Septiembre & 7 & 11.1 & 0 & 0.0 & 7 & 2.7
\end{tabular}




\begin{tabular}{lllllll} 
Octubre & 19 & 30.2 & 0 & 0.0 & 19 & 7.3 \\
Noviembre & 19 & 30.2 & 3 & 1.5 & 22 & 8.4 \\
Diciembre & 15 & 23.8 & 2 & 1.0 & 17 & 6.5 \\
\hline Total & 63 & 100.0 & 198 & 100.0 & 261 & 100.0 \\
\hline
\end{tabular}

Fuente: Elaboración propia (2014)

Es importante destacar que de las 261 notas analizadas, los hallazgos nos indican que en la totalidad de las mismas no se incluye el nombre del periodista o del encargado de su redacción. Esto indica que los responsables de administrar estos blogs, adoptan medidas precautorias para salvaguardar la integridad de quienes divulgan esta información, o bien que los propios diarios o medios formales omiten el nombre de sus reporteros o colaboradores para protegerles de posibles represalias.

\subsection{Estructura de la noticia}

Como parte de esta investigación se analizó si las notas publicadas en estos blogs cumplen con los requisitos mínimos estructurales de la redacción periodística. En este sentido se encontró que en 253 de las 261 notas (96.9 por ciento) presentan titular; mientras que apenas 8 (3.1 por ciento) no lo incluyen.

Además, se evaluó si las notas publicadas en estos sitios donde se difunde información del narcotráfico incluyen el lead; es decir, el primer párrafo de la nota que cumple la función de responder a las preguntas básicas del periodismo -que, cómo, cuándo, dónde y porqué-. En relación a esto, los datos indican que 143 de las 261 notas analizadas (54.8 por ciento) cuentan con este elemento; en 118 notas (45.2 por ciento) este elemento se omite.

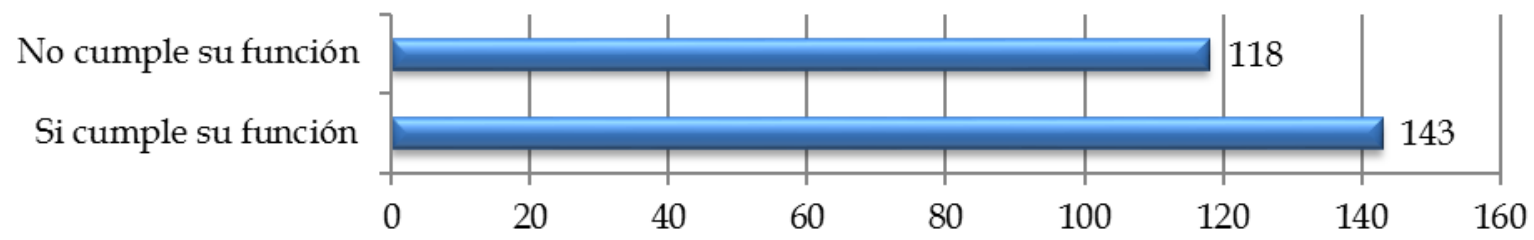

Gráfico 2. El Lead de la nota publicada cumple su función Fuente: Elaboración propia (2014)

Con el fin de saber si las notas cumplen la función de informar se establecieron dos clasificaciones de acuerdo a la presentación y extensión de la misma: completa y breve. La nota completa cumple con su función principal de informar y por otro lado la breve solo menciona lo más relevante de la nota o dirige al lector hacia otra página a través de hipervínculos. En este sentido, los resultados indican que de 261 notas analizadas, 164 de las mismas (62.8 por ciento) son presentadas de manera completa; es decir, con todos los datos relevantes y necesarios para facilitar la interpretación del hecho por parte del lector. Por otro lado, 97 notas (37.2 por ciento) son divulgadas de manera breve. 


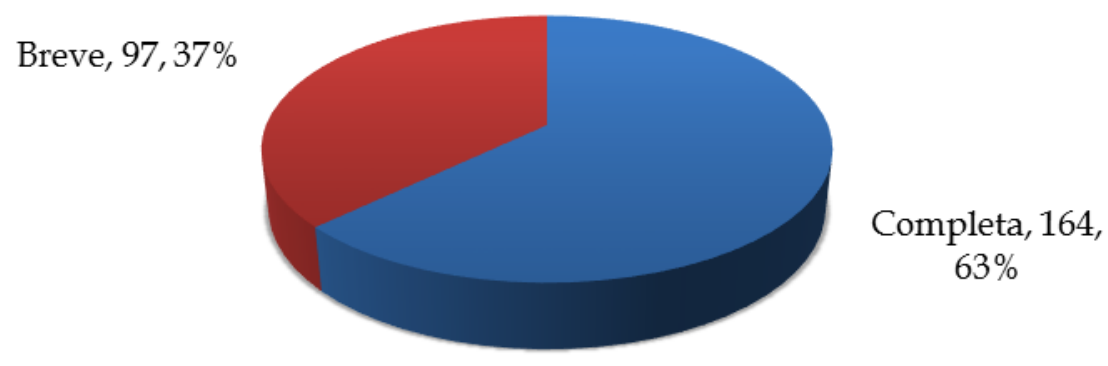

Gráfico 3. Tipo de nota publicada

Fuente: Elaboración propia (2014)

El internet se distingue de otros medios, porque se pueden combinar distintos recursos para complementar una nota; es decir, que en uno sola noticia se pueden presentar textos, fotografías, videos y audios con la finalidad de transmitir la información de una manera más eficaz. Los resultados del análisis realizado indican que en 186 de las 261 notas analizadas (71.3 por ciento) la información textual se complementa con fotografías; mientras que en 53 notas ( 20.3 por ciento) solo aparece de forma escrita.

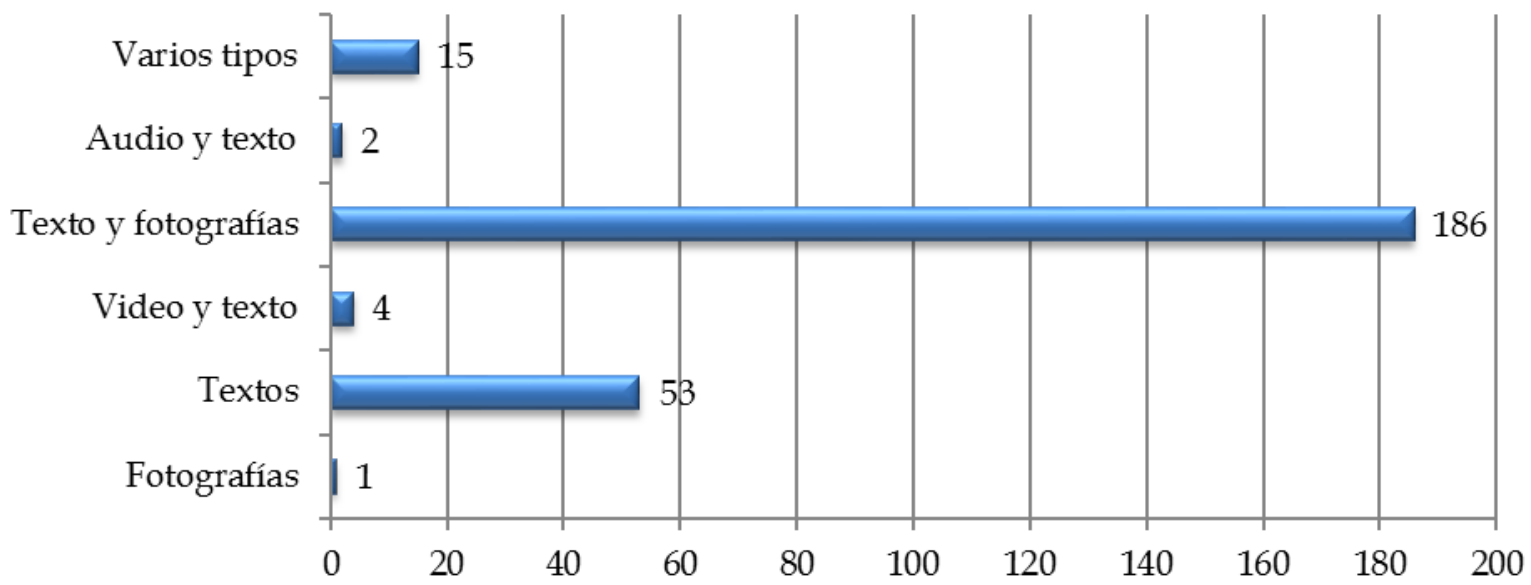

Gráfico 4. Tipo de material publicado en los blogs

Fuente: Elaboración propia (2014)

En lo que respecta a las fotografías, los datos indican que de las 201 notas que incluyen este tipo de material (se consideran las 186 que incluyen texto y fotografías; 14 que incluyen varios tipos de material y una que contiene imágenes en su totalidad) en 178 casos aparece solo una fotografía; en 11 casos dos, mientras que en 12 casos aparecen 3 o más imágenes.

Al clasificarlas, se encontró que en 91 notas las imágenes publicadas pretenden informar sobre evento violentos en diversas comunidades; en 52 casos se presenta la figura del delincuente; en 29 ocasiones son fotografías de ubicación y, en 15 notas, se divulga la figura de la víctima. En lo que respecta al origen de la información el 50 por ciento de las fotografías provienen de fuentes anónimas que no permiten 
comprobar su autenticidad; 46 de medios de comunicación y 26 tienen su origen en las organizaciones del crimen organizado.

En lo que corresponde a las 53 notas que son publicadas empleando el texto cómo único recurso informativo, los datos indican que la extensión promedio de las mismas es de 9 párrafos. Así mismo, de las 13 notas analizadas en las que en su presentación se incluye un video, se encontró que la duración promedio de los mismos es de 25 segundos y corresponden en su mayoría a presentaciones de fotografías (6 videos); presentaciones de sucesos violentos explícitos (6 videos) y una recreación.

Algunas de las notas publicadas en estos sitios son complementadas con audios o grabaciones; en este sentido se encontró que en apenas 7 ocasiones aparece este tipo de material. De las mismas, 3 de ellas corresponden a noticias grabadas. Así mismo, el origen de los mismos en su mayoría anónimos.

Por otro lado, otro aspecto importante dentro de los blogs es la publicidad. Es importante destacar que este tipo de anuncios son responsabilidad del proveedor del servicio de "hosting" -en su mayoría gratuitos- quienes agregan estos elementos a los sitios y no el administrador del mismo; sin embargo, resulta interesante su análisis por el prestigio y reconocimiento de las marcas anunciadas en estas páginas. De las 261 notas analizadas, se encontró que en 7 de cada 10 (73.9 por ciento) la información publicada incluye algún tipo de publicidad en su estructura.

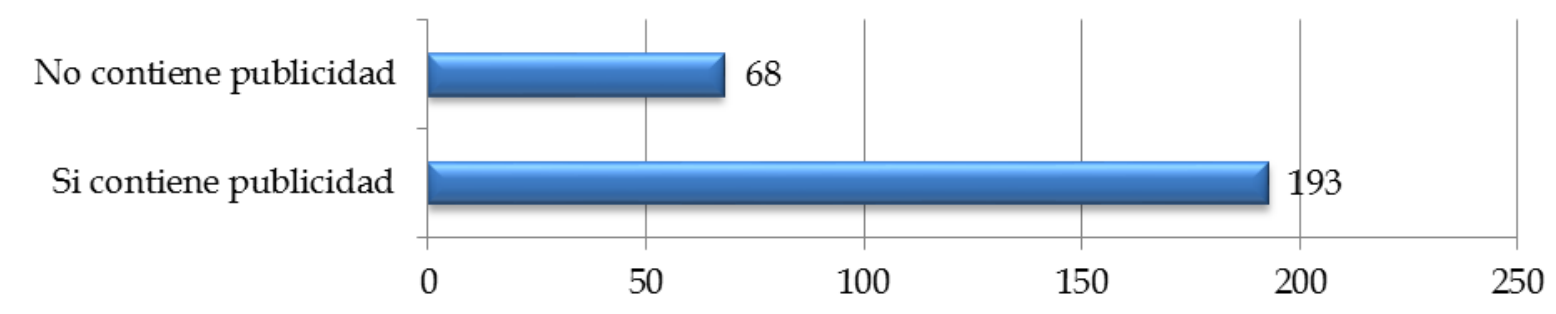

Gráfico 5. Las notas publicadas contienen publicidad Fuente: Elaboración propia (2014)

Los blogs analizados, abordan temáticas de riesgo. En su mayoría, contienen información sobre el narcotráfico y los delitos cometidos por las células del crimen organizado. En base a ello, se analizó el origen de la información brinda dada a conocer en estos blogs. De las 261 notas analizadas, 130 de estas (49 por ciento) presentan información inédita; en 61 casos (23.4 por ciento) la información es reproducida de otros medios de comunicación.

Tabla 3. Origen de la información publicada en los blogs

\begin{tabular}{lll}
\hline Origen de la información & Frecuencia & Porcentaje \\
\hline No se establece el origen & 9 & 3.4 \\
Reproducción de otros medios & 61 & 23.4 \\
Información inédita & 130 & 49.8 \\
Redes sociales & 30 & 11.5 \\
Reproducción de medios e info. & 25 & 9.6
\end{tabular}


Inédita

Info. Inédita y redes sociales $\quad 1 \quad 0.4$

Reproducción de otros medios, info. $\quad 5 \quad 1.9$

Inédita y redes sociales

\begin{tabular}{lcc}
\hline Total & 261 & 100.0 \\
\hline & Fuente: Elaboración propia (2014)
\end{tabular}

De las 91 notas analizadas que muestran información proveniente de otros medios; 78 noticias (85.7 por ciento) son extraídas de otros blogs relacionados con el crimen organizado. El resto de la información tiene su origen en revistas como Proceso que se distribuye a nivel nacional o en periódicos de la región noreste de México.

Esto resulta importante puesto que, en ocasiones, la información publicada en estos medios no cuenta con el sustento necesario desde el punto de vista periodístico. Es decir, que las noticias que por estos medios son difundidas no tienen ningún filtro o algún método que garantice la veracidad de los datos que se divulgan. Al ser evaluado el origen de los datos divulgados en las notas publicadas en estos sitios; se encontró que, en 139 de las mismas (53 por ciento) especifican la fuente informativa; mientras que en 122 (47 por ciento) este datos se omite.

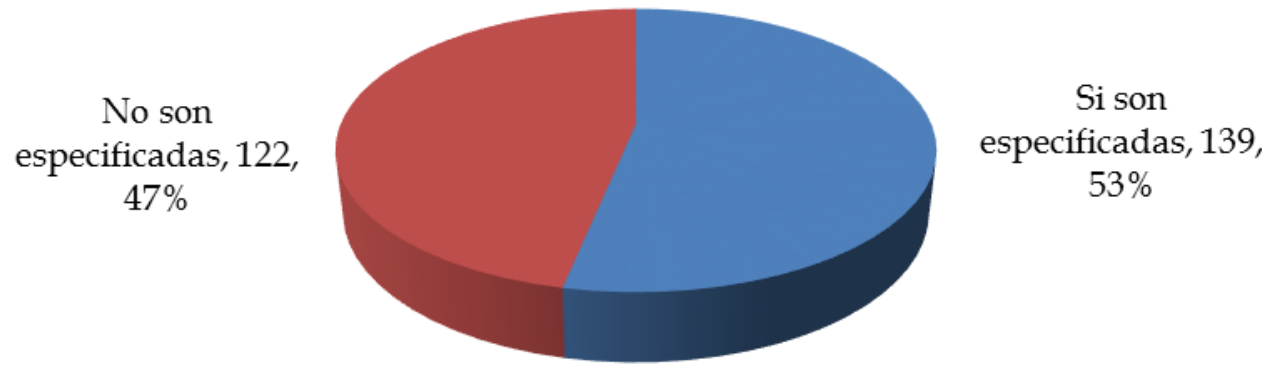

Gráfico 6. Fuentes en las notas publicadas en los blogs

Fuente: Elaboración propia (2014)

De las 139 notas en las que se especifican las fuentes de los datos en las publicaciones; en 81 casos (58.3 por ciento) la información proviene de organismos oficiales (administraciones gubernamentales o corporaciones de seguridad); mientras que la información extraoficial (trascendidos o rumores) se presentó en 29 de las notas analizadas (20.9 por ciento). Es importante destacar que en este análisis se encontró que en siete de las notas evaluadas la fuente primaria de información fueron mantas y/o pancartas dejadas en las escenas del crimen por grupos de la delincuencia organizada.

\subsection{Información respecto al fenómeno que se publica}

Según los resultados del análisis, Tamaulipas es la región del noreste de México donde se origina la mayor cantidad de información propagada en estos sitios al publicarse 147 de las 261 notas evaluadas (56.3 por ciento). Seguido por Nuevo León 
donde se originaron 53 de las noticias analizadas (20.3 por ciento) y, Coahuila donde se contabilizaron 50 notas (19.2 por ciento).

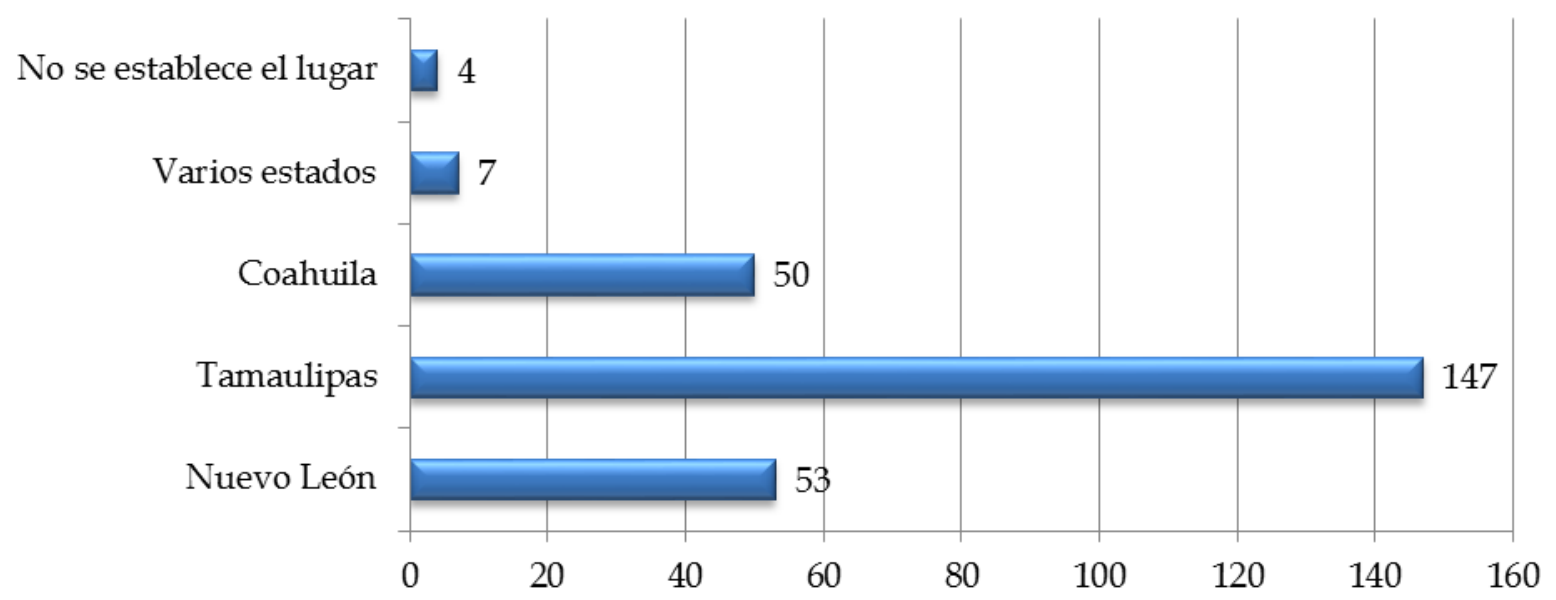

Gráfico 7. Estado de origen de las notas publicadas en los blogs

Fuente: Elaboración propia (2014)

La información divulgada a través de los blogs enfocados a difundir las actividades y crimines efectuados por las células del crimen organizado en el noreste de México, se caracteriza por el empleo de imágenes crudas y sin censura donde se establece la magnitud de los hechos. En ese sentido, los resultados indican que en 62 de las 261 noticias evaluadas ( 24 por ciento) se incluyen imágenes de este tipo; mientras que en 199 (76 por ciento) no se utiliza este recurso.

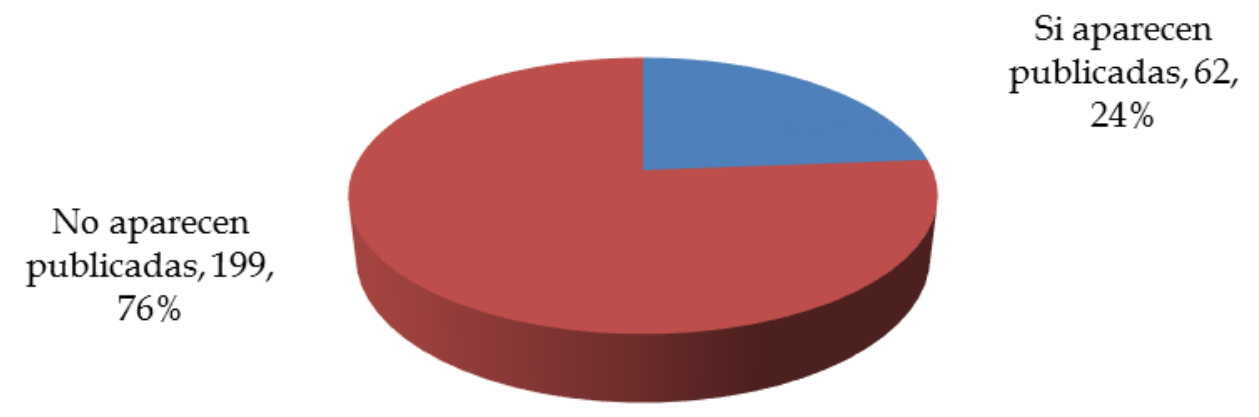

Gráfico 8. Publicación de imágenes crudas en las notas divulgadas en los blogs Fuente: Elaboración propia (2014)

En las 62 notas analizadas que publican imágenes con crudeza, en 36 de ellas -58.1 por ciento- son referentes a asesinatos. Los enfrentamientos son publicados en 19 ocasiones. Mientras que en 4.8 por ciento de las imágenes muestras a personas golpeadas, misma cifra que las imágenes de cadáveres. 


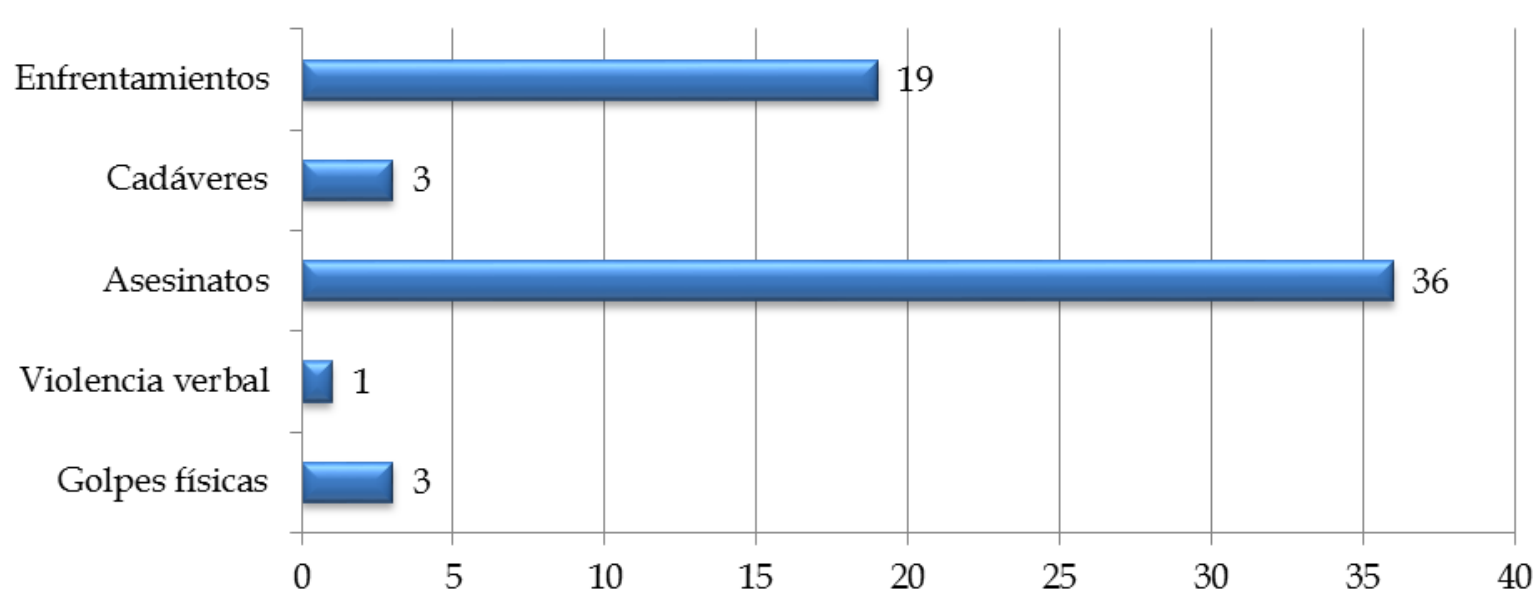

Gráfico 9. Tipo de imágenes crudas en las notas divulgadas en los blogs. Fuente: Elaboración propia (2014)

Los resultados del análisis indican que en 182 de las notas evaluadas se divulga algún tipo de enfrentamiento armado y/o violento. En 99 notas (37.8 por ciento) se informa de dos o más crímenes relacionados con la delincuencia organizada. El delito que se presenta con mayor frecuencia es el homicidio al contabilizar 43 notas (23.6 por ciento); otros delitos como extorsión, incendio de autos, tráfico de drogas o personas o balaceras registran porcentajes inferiores. Por otra parte, en siete notas se habla respecto a operativos implementados por las autoridades para combatir a estos grupos y, en el mismo número de notas, se señala la participación de funcionarios gubernamentales en actividades de narcotráfico.

Si bien todas las noticias analizadas están ligadas con el crimen organizado, no en todos los casos se presentaron enfrentamientos entre bandas o grupos contrarios. Según la información publicada en 226 de las 261 notas analizadas mayoría (86.6 por ciento) no existió tal acto; mientras que en 35 noticias (13.4 por ciento) se afirma la existencia de conflictos entre grupos contrarios.

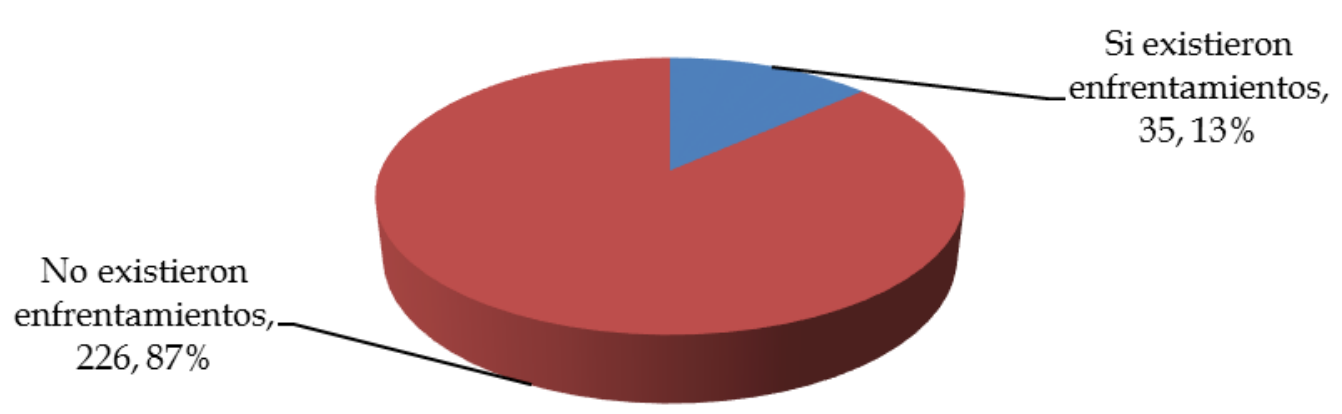

Gráfico 10. Enfrentamientos entre carteles

Fuente: Elaboración propia (2014)

De las notas en las que se afirma la existencia de un enfrentamiento entre diferentes grupos de la delincuencia organizada se encontró que en 13 de ellas (37.1 por ciento) se presentaron amenazas o disputas de territorio; en 9 casos ( 25.7 por ciento) 
enfrentamientos internos entre miembros de los carteles; mientras que en 8 notas (22.9 por ciento) se registraron varios enfrentamientos.

En base la información presentada la participación de las bandas se encontró que en la mayoría de las notas analizadas (60.9 por ciento) estos grupos de la criminalidad organizada si están involucrados en los sucesos publicados; en 4 de cada 10 notas está involucrado el grupo criminal conocido como "Los Zetas"; mientras que en 2 de cada 10 notas es el Cartel del Golfo el responsable de los sucesos divulgados. Por otra parte, en el 39.1 por ciento de las mismas la información no es suficiente para determinar si participan o no en los sucesos.

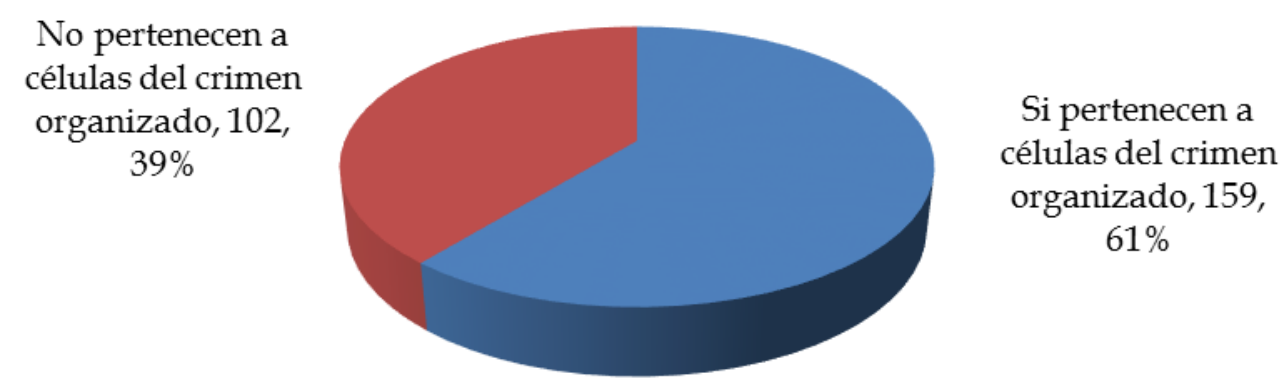

Gráfico 11. Participación de bandas del crimen organizado en el suceso Fuente: Elaboración propia (2014)

En lo que concierne al empleo de armamento, los resultados indican que en 124 de las 261 notas analizadas (48 por ciento) los criminales emplearon algún tipo de arma; es decir, en 5 de cada 10 sucesos divulgados en estos blogs los delincuentes emplearon armas de fuego. Así mismo, de las 124 notas en las que se afirma el uso de armamento, en 81 (59.1 por ciento) los delincuentes utilizaron armas de fuego (pistolas, metralletas o rifles) para cometer el crimen. Estos datos indican que los grupos de la delincuencia organizada cuentan con armamento amplio que les permite hacer frente a las autoridades o involucrarse en enfrentamientos con otros grupos de la criminalidad organizada.

No se utilizó armamento, 124 , $48 \%$

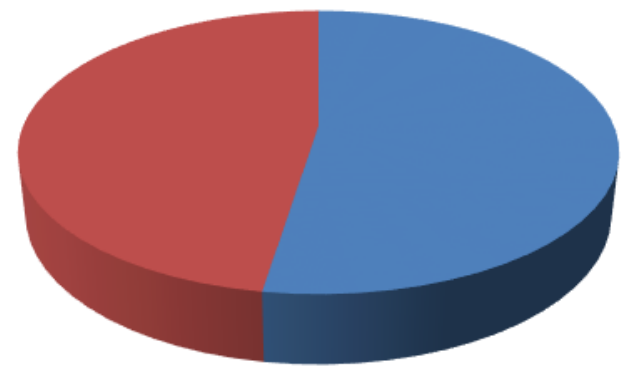

Si se utilizó armamento, 137 , $52 \%$

Gráfico 12. En la nota se establece que se empleó algún tipo de armamento Fuente: Elaboración propia (2014) 
De las acciones de las autoridades en la prevención y combate de la delincuencia organizada; en 66 de las 261 notas analizadas ( 25.3 por ciento) se afirma que hubo detenidos durante el suceso; mientras que en 195 (74.7 por ciento) las autoridades no capturaron a ningún criminal miembro de una célula de la delincuencia organizada. De las 66 notas en las que se indica la detención de un miembro del crimen organizado; en 27 de estas (41.5 por ciento) el aprehendido fue el líder del cartel; en 22 notas (33.8 por ciento) miembros ordinarios de estas células; en cinco notas se afirma la existencia de varios detenidos.

Por otra parte, en 128 de las 261 notas (49 por ciento) analizadas se afirma que los delincuentes participantes cometieron delitos previos; mientras que en 133 (51 por ciento) la información no permite establecer si los criminales participaron en actos delictivos previamente.

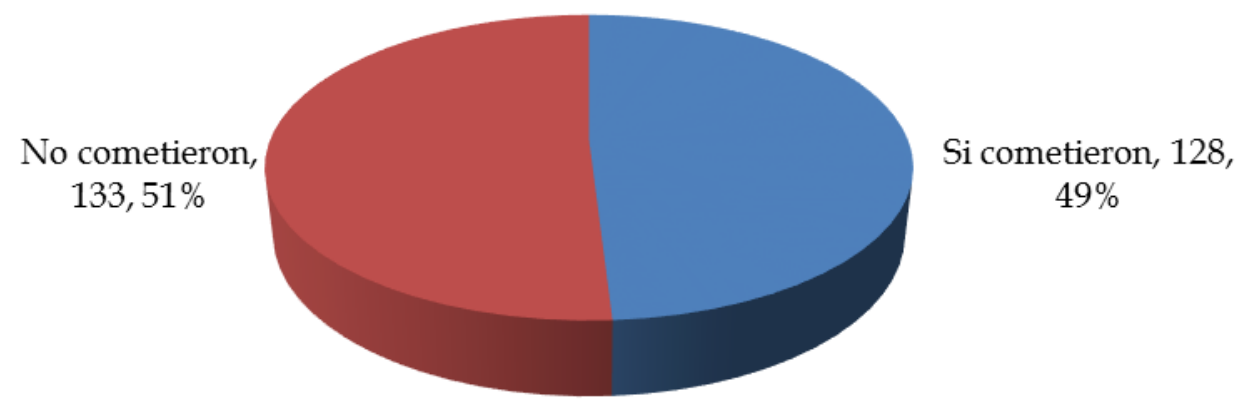

Gráfico 13. Participación en delitos previos Fuente: Elaboración propia (2014)

De las 128 notas publicadas donde se menciona si presentan actos delictivos del delincuente detenido, se analizó cuál era el suceso ilícito que ellos cometieron antes de su detención. De estas, en 29 (22.7 por ciento) la información indica que el detenido cometió un homicidio previamente; en 12 casos (9.4 por ciento) se afirma que participó en tráfico de drogas; misma cifra de aquellas noticias en las que se informa que un funcionario gubernamental está relacionado con células del crimen organizado. Así mismo, en 8 notas (6.3 por ciento) el delincuente colaboró previamente en un secuestro; en 4 notas (3.1 por ciento) la información indica su participación en balaceras, misma cifra de aquellos que se involucraron en operativos. En 48 (37.5 por ciento) de las notas divulgadas los integrantes del crimen organizado tenían más de un delito cometido previamente.

Como parte de este análisis se analizó si en la información publicada en las páginas web se establece el hallazgo de fosas donde los carteles del crimen organizado depositaban los cadáveres de sus víctimas. El resultado del análisis de las 261 publicaciones en los blogs, 11 notas mencionan que si hallaron narco-fosas.; en una de ellas se encontraron aproximadamente 100 cuerpos. 
Si fueron halladas,

$11,4 \%$

\author{
No fueron \\ halladas, $250,96 \%$
}

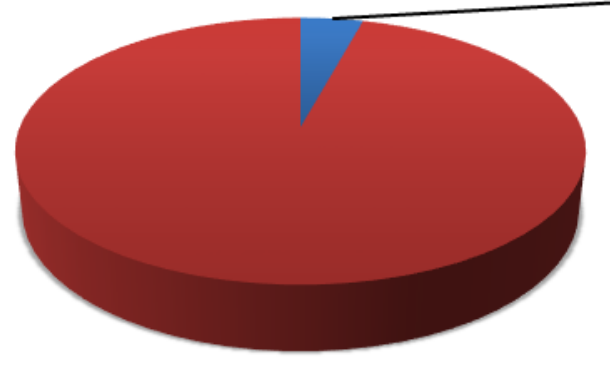

Gráfico 14. Hallazgo de narco fosas

Fuente: Elaboración propia (2014)

Con el fin de conocer la ubicación exacta de las narco-fosas, se examinaron las 11 notas que hace mención de los lugares donde fueron encontradas por las autoridades de seguridad. Cinco de las narco fosas fueron encontradas en la región norte del estado de Nuevo León, en los municipios de Zaragoza, Hidalgo y El Carmen. Una más se ubicó en el estado de Tamaulipas y, en cinco casos, se hace mención del hallazgo, sin embargo, no se establece su localización.

Por otra parte, en 34 de las 261 notas analizadas, se establece que los grupos de la criminalidad organizada lanzaron amenazas. En 14 de estas se observa que estas se refieren a conflictos y amenazas entre carteles; en dos casos contra familiares de narcotraficantes, cifra similar que aquellas dirigidas a corporaciones de seguridad y dirigentes políticos; en cuatro casos existieron varios tipos de amenazas.

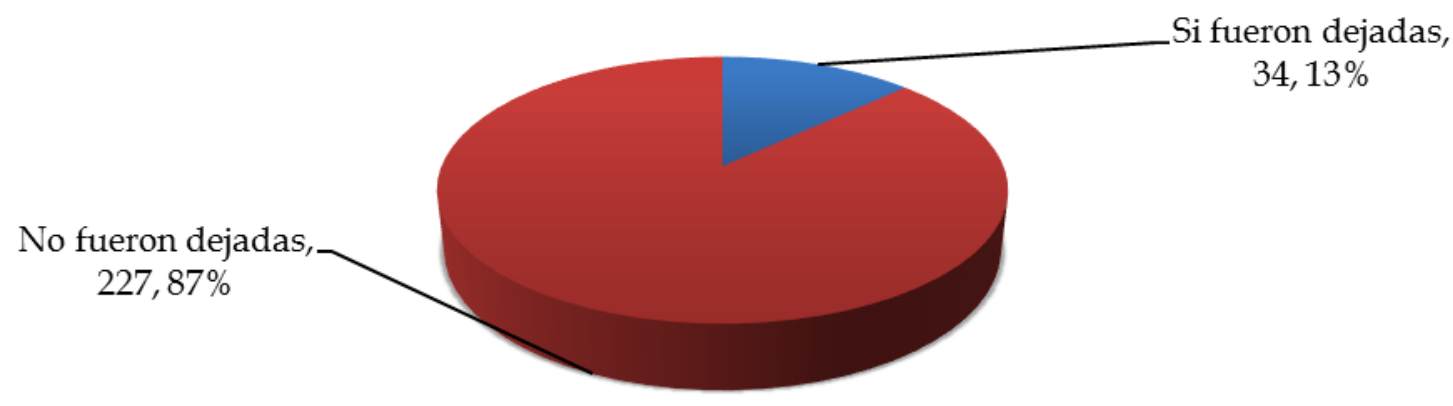

Gráfico 15. Amenazas dejadas en el lugar del suceso Fuente: Elaboración propia (2014)

Respecto al lugar donde fueron dejados mensajes intimidatorios y amenazas por parte del crimen organizado, los resultados señalan que en 12 de las 34 notas (35.3 por ciento) estos corresponden a "narco mantas" (mensajes de gran dimensión estampados en telas y colocados sobre puentes peatonales o sitios de gran visibilidad para los transeúntes); en 8 casos ( 23.5 por ciento) a cárteles; en 3 notas (8.8. por ciento) a mensajes clavados sobre personas ejecutadas por ellos mismos; mientras que en 9 notas (26.5 por ciento) no se establece el lugar. 


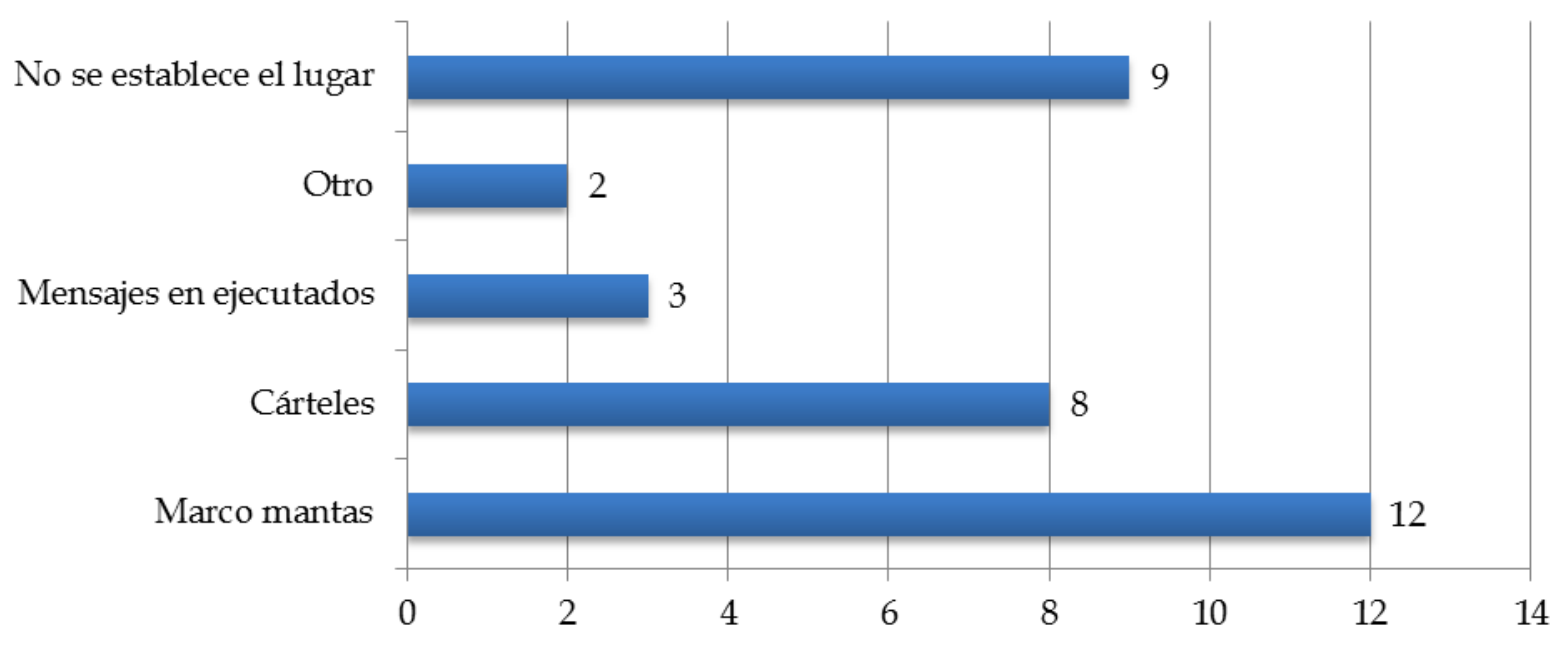

Gráfico 16. Lugar donde fueron dejadas las amenazas Fuente: Elaboración propia (2014)

De las 261 notas analizadas se encontró que en 167 (64 por ciento) se menciona la participación de una corporación de seguridad, mientras que en 94 notas (36 por ciento) no se mencionaron.

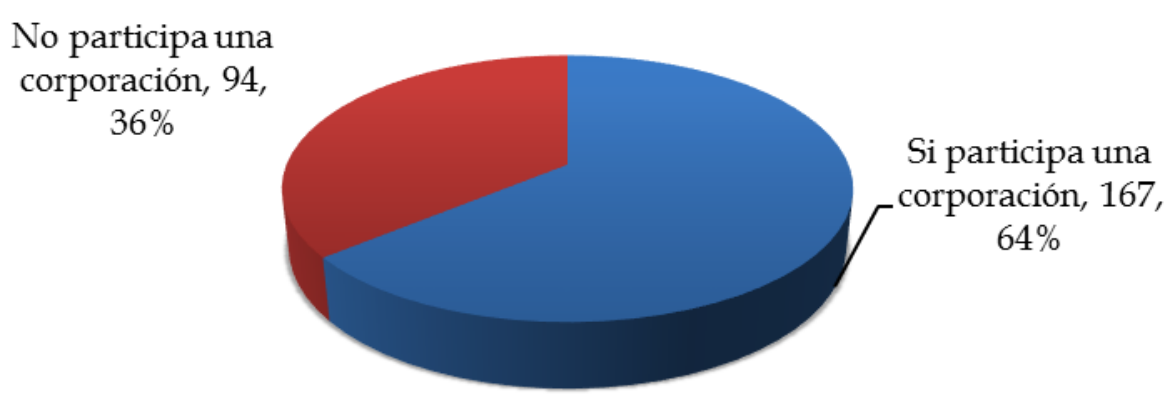

Gráfico 17. Mención de corporaciones de seguridad en las notas publicadas Fuente: Elaboración propia (2014)

En 51 notas (30.5 por ciento), la información establece la participación de una corporación de seguridad de nivel estatal; en 42 (25.1 por ciento) corresponde a una institución del nivel federal; en 27 noticias (16.2 por ciento) se involucran autoridades de todos los niveles y en 13 (7.8 por ciento) del nivel local o municipal. Por otro lado, en 20 notas ( 12 por ciento) combinaron esfuerzos autoridades estatales y federales; en ocho casos (4.8 por ciento) participaron instituciones municipales y estatales. 


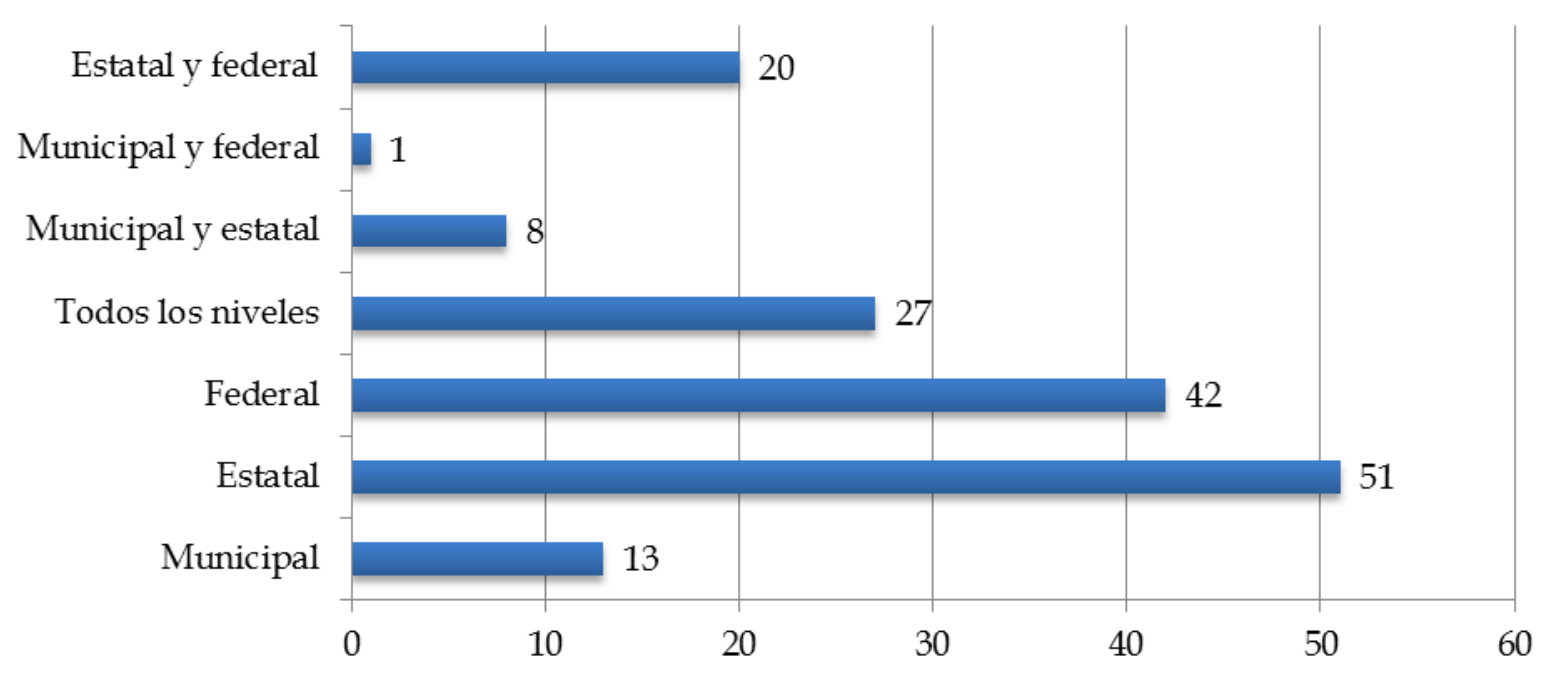

Gráfico 18. Nivel de la corporación de seguridad participante Fuente: Elaboración propia (2014)

Respecto a las corporaciones de seguridad participantes en los eventos divulgados en las notas analizadas; se identificó que en 27 de las 167 noticias (16.2 por ciento) en las que se establece la intervención de la autoridades se vieron involucradas distintas instituciones. Así mismo, en 21 notas (12.6 por ciento) participó la Secretaría de Defensa Nacional (SEDENA); misma cifra de aquellas noticias en las que se vieron involucradas autoridades federales.

Por otro lado, las autoridades estatales participaron en 18 casos (10.8 por ciento); la Procuraduría General de Justicia del Estado de Nuevo León en 16 (9.6 por ciento); la Secretaría de Seguridad Pública (sin mencionar el estado) se mencionó en 12 notas (7.2 por ciento). Otras corporaciones como Fuerza Civil del Estado de Nuevo León aparecieron en 9 casos (5.4 por ciento); el Ministerio Público en 8 (4.8 por ciento); la Procuraduría General de la República Mexicana en 4 (2.4 por ciento).

Tabla 4. Corporación de seguridad participante

\begin{tabular}{lll}
\hline Corporación & Frecuencia & Porcentaje \\
\hline Agencia Estatal de Investigación & 3 & 1.8 \\
Autoridades estatales & 18 & 10.8 \\
Autoridades federales & 21 & 12.6 \\
Autoridades municipales & 5 & 3.0 \\
C4 & 1 & 0.6 \\
Comisión Estatal de Seguridad & 1 & 0.6 \\
Corte Federal de Brownsville (Texas) & 1 & 0.6 \\
Fuerza Civil & 9 & 5.4 \\
GROM & 1 & 0.6 \\
Ministerio Público & 8 & 4.8 \\
No se menciona el nombre & 14 & 8.4 \\
PGJ Nuevo León & 16 & 9.6 \\
PGJ Tamaulipas & 1 & 0.6 \\
PGR & 4 & 2.4
\end{tabular}




\begin{tabular}{lll} 
Protección Civil & 1 & 0.6 \\
SAGARPA & 1 & 0.6 \\
Secretaría de Seguridad Pública & 12 & 7.2 \\
SEDENA & 21 & 12.6 \\
SEIDO & 2 & 1.2 \\
Varias corporaciones & 27 & 16.2 \\
\hline Total & 167 & 100.0 \\
\hline *Se consideran sólo las 167 & notas en las que se menciona la \\
participación de una corporación de seguridad. Fuente: Elaboración \\
propia (2014)
\end{tabular}

Una vez que se analizó en cuántas notas se afirmaba la participación de una institución de seguridad; se evaluó cuáles fueron las acciones de estas en el suceso. Respecto a las acciones clasificadas como positivas, se encontró que en 38 (24.4 por ciento) se llevó a cabo la investigación en el lugar de los hechos; en 35 (22.4 por ciento) fueron capturados los delincuentes responsables, misma cifra de aquellas notas en las que se afirma su participación en varias acciones; en 10 noticias (6.4 por ciento) implementaron operativos y/o retenes; en 7 casos (4.5 por ciento) brindaron atención a víctimas civiles.

Tabla 5. Acciones de la corporaciones de seguridad participantes.

\begin{tabular}{lll}
\hline Acciones de la corporación & Frecuencia & Porcentaje \\
\hline Captura de los delincuentes & 35 & 22.4 \\
Atención a víctimas civiles & 7 & 4.5 \\
Investigación en el lugar de los hechos & 38 & 24.4 \\
Recuperación de armamento & 4 & 2.6 \\
Decomiso de drogas & 1 & 0.6 \\
Vigilancia & 6 & 3.8 \\
Operativos y/o retenes & 10 & 6.4 \\
Ninguna & 9 & 5.8 \\
Otra & 11 & 7.1 \\
Varias acciones & 35 & 22.4 \\
\hline Total & 167 & 100.0 \\
\hline *Se consideran sólo las 167 notas en las que se menciona la \\
participación de una corporación de seguridad. Fuente: Elaboración \\
propia (2014)
\end{tabular}

Por otra parte, en las notas analizadas también se encontró información respecto a la participación de diferentes corporaciones de seguridad municipal, estatal y federal en actividades ligadas al crimen organizado. En ese sentido, la evaluación indica que en 22 notas (13 por ciento) de las 167 en las que se afirma la intervención de una institución de seguridad, ésta tenía nexos con grupos de la delincuencia. 
No tienen nexos con el CO, 147, $87 \%$

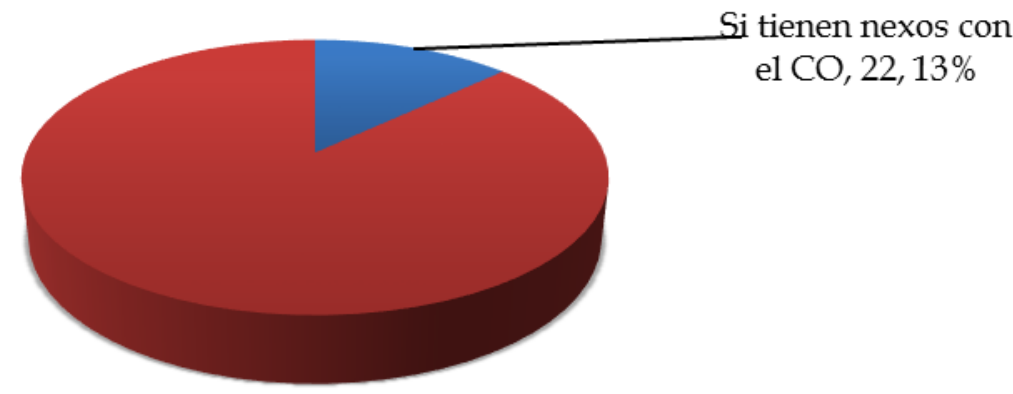

Gráfica 19. Nexos de las autoridades con grupos del crimen organizado Fuente: Elaboración propia (2014)

De las 22 notas en donde se hace mención sobre la existencia de vínculos entre las corporaciones de seguridad y los grupos de la delincuencia organizada, el monitoreo o vigilancia (denominado coloquialmente como halconeo) es el que se presenta con mayor frecuencia al contabilizar 5 notas (22.7 por ciento), misma cifra de aquellas notas en las que se indican varios tipos de nexos. Por otro lado, en 4 notas (18.2 por ciento) se señala la existencia de sobornos y/o pagos; mientras que en 4 notas (18.2 por ciento) se indica que las autoridades brindan protección a los grupos del crimen organizado; en 3 notas (13.6 por ciento) se afirma la existencia de infiltrados de la delincuencia en las instituciones de seguridad.

En su totalidad, los sucesos divulgados en los blogs analizados están relacionados con actividades realizadas por grupos del crimen organizado; sin embargo, no en todas estas noticias se da información respecto a los involucrados, en algunos casos, la información publicada sólo informa el hecho sin poner atención en los participantes. Los resultados del análisis indican que en 126 de las 261 notas analizadas (48.3 por ciento) existieron sujetos implicados en el suceso.

No se establecen implicados, 135, $52 \%$

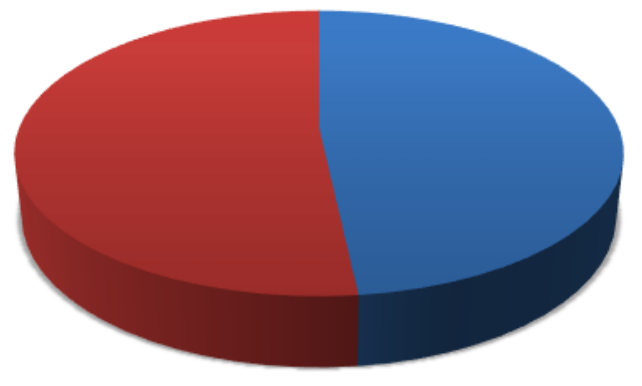

Si existen

implicados, 126, $48 \%$

Gráfica 20. Sujetos implicados en el suceso publicado.

Fuente: Elaboración propia (2014)

De acuerdo a los resultados del análisis, en cada uno de los casos divulgados en las notas publicadas en los blogs participan en promedio tres individuos. De las 126 notas en 66 (52.4 por ciento) el criminal actuó en solitario. Mientras que en 47 notas 
(37.3 por ciento) trabajaban en grupos de dos a cinco individuos y, en 13 noticias (10.3 por ciento) en grupos de seis o más individuos.

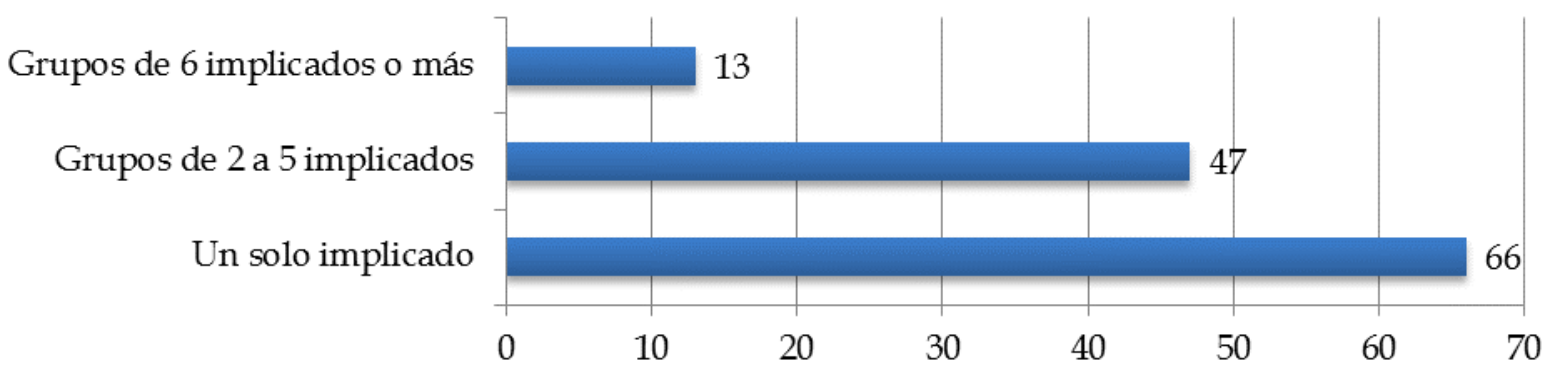

Gráfica 21. Cantidad de sujetos implicados en el suceso publicado Fuente: Elaboración propia (2014)

En cuanto al género de los implicados, en 108 de las 126 notas (85.7 por ciento) estos pertenecen al género masculino; apenas en 9 notas (7.1 por ciento) se indica la participación de mujeres y, en 7 casos (5.6 por ciento) se involucran individuos de ambos géneros.

Así mismo, en 101 notas (38.7 por ciento) la información publicada incluye la edad de los sujetos implicados. Los resultados indican que en 46 de las 101 notas (45.5 por ciento) los participantes son jóvenes adultos (22 a 35 años de edad); en 36 casos (35.6 por ciento) los involucrados son adultos (35 a 55 años); en 9 casos (8.9 por ciento) participan sujetos de diversas edades, mientras que en 4 notas (4 por ciento) se afirma la participación de adultos mayores. Apenas en 5 notas se señala la participación de jóvenes (hasta 21 años) y, en un caso, se sostiene que un menor de edad estuvo involucrado.

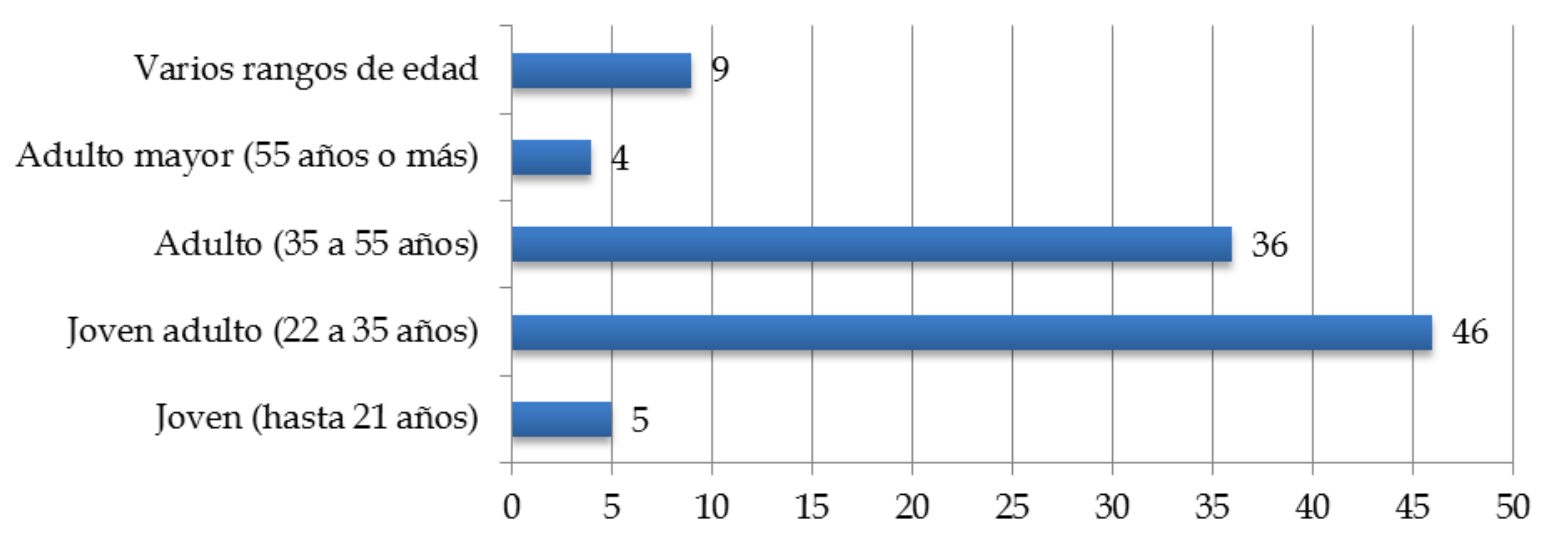

Gráfica 22. Rango de edad de los sujetos implicados

Fuente: Elaboración propia (2014)

Otro aspecto analizado durante el desarrollo de esta investigación es el oficio desempeñado por los presuntos delincuentes antes de integrarse al crimen organizado o bien, si desarrollaban ambas actividades a la par. En ese sentido, se encontró que solamente en 57 de las notas (21.8 por ciento) los datos permiten establecer el oficio previo. 


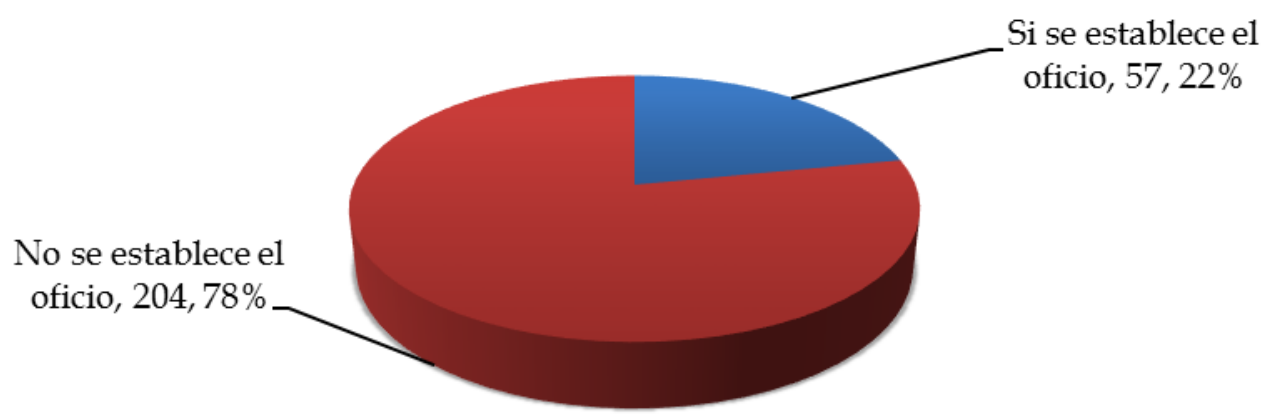

Gráfica 23. Oficio de los implicados

Fuente: Elaboración propia (2014)

Para los resultados obtenidos del análisis de los oficios de los implicados en diversos actos delictivos, se consideró primero clasificar si tenían algún otro oficio además de dedicarse al delito del narcotráfico y, posteriormente, registra las ocupaciones adicionales de los implicados. En total los resultados señalan que 261 notas, solamente en 57 se menciona el oficio de los implicados.

De este elenco de actividades clasificadas dentro del análisis de los blogs, se encontró que en 32 casos (56.1 por ciento) el implicado ya formaba parte de una célula del crimen organizado; cinco (8.8 por ciento) eran miembros de la policía; en tres casos (5.3 por ciento) se implicaba al gobernador del estado; misma cifra de aquellas notas en las que se menciona la participación de algún miembro de la administración; en dos casos (3.5 por ciento) se indica la colaboración de alcaldes.

Tabla 6. Oficio de los implicados

\begin{tabular}{lll}
\hline Oficio del implicado & Frecuencia & Porcentaje \\
\hline Alcalde & 2 & 3.5 \\
Chofer & 1 & 1.8 \\
Contador & 2 & 3.5 \\
Director de comunicaciones & 1 & 1.8 \\
Empresario & 1 & 1.8 \\
Estudiante & 1 & 1.8 \\
Gobernador & 3 & 5.3 \\
Implicado en el crimen organizado & 32 & 56.1 \\
$\quad$ Miembro de administración & 3 & 5.3 \\
Miembro de la policía & 5 & 8.8 \\
Operador & 1 & 1.8 \\
Político & 2 & 3.5 \\
Repartidor & 1 & 1.8 \\
Taxista & 1 & 1.8 \\
Ventas & 1 & 1.8 \\
\hline Total & 261 & 100.0 \\
\hline *Se consideran sólo las 57 notas en las que se establece el oficio de los \\
implicados.
\end{tabular}


Por último, al analizar la participación de la pareja sentimental de los miembros del crimen organizado; en relación a esto se encontró que en 257 noticias (98.5 por ciento) no hubo intervención, mientras que la frecuencia restante de las notas en las que si participó la pareja, fue de 4 frecuencias, es decir, el 1.5 por ciento del universo analizado.

\section{CONCLUSIONES}

La región Noreste de la República Mexicana es una de las zonas en donde la delincuencia organizada ha tenido un fuerte impacto delictivo tanto en el ámbito de homicidios; tráfico de personas y armas; secuestros y plagios. En esta región de México, carteles como el "Del Golfo" o "Los Zetas" operan impunemente cometiendo actos violentos a plena luz del día, tal como se constata en los blogs, cuyo objetivo principal es la difusión de los crímenes cometidos por estas células. Una vez finalizado el análisis de 261 notas publicadas en estos sitios se concluye que:

La información que circula en la red carece de filtros y/o control. A tales contenidos, tienen acceso jóvenes o niños que a través de la red conocen la realidad delictiva y el esquema de anti-valores e impunidad de los cuales se ufanan los miembros de la criminalidad. Estos sitios son visitados y controlados por los miembros de las células del crimen organizado, quienes difunden sus delitos; riqueza y desafíos bien sea contra el Estado mexicano o contra sus grupos rivales, sin ningún tipo de cortapisa.

Resulta preocupante la "viralización" que a través de las redes sociales se tiene en México, en contenidos violentos y delictivos generados y transmitidos desde el anonimato por blogs procedentes de ciudadanos y por diversos grupos de la criminalidad. El Estado mexicano, tal como sucede en otras latitudes, e incluso en países de alto desarrollo, no ha podido frenar por razones legales y técnicas la apología del delito que en ellos se hace y la exaltación de estilos de vida y antivalores que el dinero fácil gesta al interior de las mafias.

$\mathrm{Al}$ analizar la frecuencia con la que esta información es divulgada a través de blogs en los que no existe ningún tipo de censura, se encontró que de mayo a diciembre del año 2013 se publicaron 63 noticias relacionadas con el crimen organizado; esto equivale a un promedio de ocho noticias mensuales (una cada cuatro días); mientras que para 2014 se contabilizaron 198; es decir, una media de 16 notas por mes (una cada dos días). En general, los datos indican se que en promedio son publicadas 13 notas mensuales; aproximadamente una nota cada tres días. El sitio más activo, es el denominado "tierradelnarco.com" que contabilizó un mayor número de noticias publicadas durante el periodo de análisis (109 noticias).

Una gran cantidad de la información publicada a través de estos sitios es inédita; es decir, no ha sido divulgada a través de ningún otro medio. Esto parece indicar que la administración de estos sitios está bajo el control de grupos de la delincuencia organizada o, en su defecto, son los mismos miembros de estas organizaciones quienes "filtran" la información a los responsables de la administración de estos sitios.

Por otro lado, se analizó cuál es la forma en la que estos hechos son divulgados y si es que cumplen con los criterios mínimos para el ejercicio periodístico. En este sentido se encontró que la totalidad de las notas publicadas a través de estas páginas 
aparecen sin firmar; esto se debe a que el medio original de publicación, del cual son extraídas estas notas, las divulga sin la firma del periodista a cargo de su redacción con la finalidad de evitar posibles represalias. Así mismo, cuando estas son inéditas el responsable de subir la información o quien administra el sitio, omite el nombre del autor.

En lo que respecta al apartado gráfico; se encontró que en 217 de las 261 notas evaluadas no se presentaban imágenes con un alto grado de crudeza. Empero, la imágenes publicadas presentaban la figura de los delincuentes; a los mismos mostrando artefactos, siendo detenidos o, inclusive, durante celebraciones de los grupos de la criminalidad organizada. De las notas que son complementadas con imágenes crudas, éstas ilustran la violencia con la cual se enfrentan distintos células del crimen organizado.

Las amenazas entre distintos cárteles y las disputas de territorio son las principales actividades difundidas en la información analizada; es decir, en 4 de cada 10 notas evaluadas se establece un conflicto de este tipo. Estos conflictos -contrario a la creencia popular- no son perpetrados a altas horas de la noche; si no que se presentan en cualquier momento del día. Por otro lado, en 3 de cada 10 notas se establece la existencia de conflictos al interno de estas células.

Al observar la participación de las diferentes bandas del crimen organizado, se encontró que la organización conocida como "Los Zetas", operantes en el noreste de México y sur del estado de Texas (E.U.) es la más activa. Seguido de "El Cartel del Golfo". Según las notas analizadas, estas bandas de la criminalidad cuentan con armamento de alto calibre; principalmente, armas de fuego.

La gran parte de las notas publicadas en estos sitios aborda los incidentes sin considerar si se presentaron detenidos o no. Sin embargo, es importante destacar que cuando existen detenidos, estos son del género masculino, con una edad aproximada entre los 22 y los 35 años y en su mayoría corresponden a líderes del cartel. Así mismo, la información analizada permite concluir que los individuos detenidos cuentan con un expediente criminal en el que se incluyen delitos como tráfico de drogas y narcotráfico.

En cuanto a la participación de corporaciones de seguridad en los hechos divulgados, los datos señalan que las autoridad del nivel estatal y federal fueron las que estuvieron más activas; debido, entre otras razones, al tipo de delincuentes a los que se enfrentan.

Los hechos violentos y la difusión de infiltrados del crimen organizado en las corporaciones de seguridad, han provocado que la desconfianza de la ciudadanía en estas instituciones se incremente. Sin embargo, contrario a esta creencia, la información publicada en los blogs del narcotráfico, indica que en 9 de cada 10 casos en los que se indica la participación de alguna autoridad, esta no se encuentra relacionada con las células de la delincuencia. 


\section{REFERENCIAS}

\section{Libros}

\section{Libros completos}

Crucianelli, S. (2013) Herramientas digitales para periodistas. Estados Unidos: Centro Knight para el Periodismo en las Américas de la Universidad de Texas.

Hernández, S. R.; Fernández, C. C. \& Baptista, L. P. (2010) Metodología de la Investigación. México: Mc Graw Hill.

Leñero, V. \& Marín, C. (1986) Manual de Periodismo. México: Editorial Grijalbo

Medel, M. (2010) Periodismo en Tiempos de Amenazas, Censura y Violencia. Estados Unidos: McCormick Foundation.

Parrat, S. (2007) Géneros periodísticos en prensa. España: Universidad Complutense de Madrid.

\section{Capítulo de un libro o entrada de un libro de consulta}

Bridges, T. (2010) Coverage of Drug Trafficking and Organized Crimen in Latin America and the Caribbean, en $8^{\text {th }}$ Austin Forum on Journalism in the Americas (Eds.). Coverage of Drug Trafficking and Organized Crime in Latin America and the Caribbean (pp. 6-18). Estados Unidos: Open Society Foundation

Fundación Mexicana de Periodismo de Investigación MEPI. (2010) Mexico: The New Spiral of Silence, en $8^{\text {th }}$ Austin Forum on Journalism in the Americas (Eds.). Coverage of Drug Trafficking and Organized Crimn in Latin America and the Caribbean (pp. 53-61). Estados Unidos: Open Society Foundation

Monsiváis, C. (2005) La búsqueda de la calidad periodística en los medios audiovisuales y las demandas sociales en América Latina, en Memorias del Seminario realizado por la CAF y la Fundación Nuevo Periodismo Iberoamericano. México: Fundación Nuevo Periodismo.

Sierra, A. (2010) Peligros y Paradojas de la Cobertura del Narcotráfico, en Medel, M. (Eds.) Periodismo en Tiempos de Amenazas, Censura y Violencia (pp. 9-14). Estados Unidos: McCormick Foundation.

\section{Artículos}

Restrepo, D. J. (2013) ¿Los twiteros son periodistas?, en Consultorio Ético de la FNPI. Recuperado de: www.fnpi.org. Consultado el: 15/10/2014 


\section{AUTOR/ES:}

\section{Patricia Liliana Cerda Pérez:}

Comunicóloga por la Universidad Autónoma de Nuevo León. Licenciada y doctora en Ciencias de la Información por la Universidad Complutense de Madrid. Miembro del Sistema Nacional de Investigadores (Nivel II). Coordinadora del Centro de Investigación para la Comunicación de la Facultad de Ciencias de la Comunicación de la Universidad Autónoma de Nuevo León. Ha publicado más de 77 artículos de divulgación científica y es autora de 14 libros editados bajo la línea de análisis de la violencia, siendo los más recientes "El Suicidio en Nuevo León. Rutas, Teorías y Diagnóstico Integral. Estudio Longitudinal 2004-2010"; “Percepción y Realidad del Secuestro en Nuevo León" y "Prisión y Familia".

José Gregorio Jr. Alvarado Pérez:

Licenciado en Ciencias de la Comunicación, con acentuación en Información y Máster en Ciencias de la Comunicación con Especialidad en Administración de Nuevas Tecnologías por la Universidad Autónoma de Nuevo León. Es Profesor en la misma Facultad de Ciencias de la Comunicación de la UANL. Además se desempeña como investigador en el Centro de Investigación de la Comunicación coordinado por la Doctora Patricia Liliana Cerda Pérez, con la que ha colaborado en diez análisis sobre violencia intrafamiliar, escolar y comunitaria, así como en estudios sobre el Suicidio y el Secuestro en Nuevo León, siendo "Prisión y Familia" el documento más reciente. 